\title{
Symbiotic Effectivity of Dual and Tripartite Associations on Soybean (Glycine max L. Merr.) Cultivars Inoculated With Bradyrhizobium japonicum and AM Fungi
}

\begin{abstract}
Tünde Takács ${ }^{1 *}$, Imre Cseresnyés ${ }^{1 *}$, Ramóna Kovács ${ }^{1}$, István Parádi ${ }^{1,2}$, Bettina Kelemen ${ }^{1}$, Tibor Szili-Kovács ${ }^{1}$ and Anna Füzy ${ }^{1}$
\end{abstract}

'Institute for Soil Sciences and Agricultural Chemistry, Centre for Agricultural Research, Hungarian Academy of Sciences, Budapest, Hungary, ${ }^{2}$ Department of Plant Physiology and Molecular Plant Biology, Institute of Biology, Eötvös Loránd University, Budapest, Hungary

Soybean (Glycine max L. Merr.) is regarded worldwide as indisputably one of the most important crops for human food and animal feed. The presence of symbiotic bacteria and fungi is essential for soybean breeding, especially in low-input agricultural systems. Research on the cooperation between different microbial symbionts is a key to understanding how the health and productivity of the plant is supported. The symbiotic effectivity of dual and tripartite symbiotic agents was investigated in two pot experiments on different soybean cultivars with special regard to compatibility. In the Selection experiment, two out of sixteen soybean cultivars (Aliz, Emese) were chosen on the basis of their drought tolerance and used in all the other investigations. In the Compatibility experiment, the compatible coupling of symbiotic partners was selected based on the efficiency of single and co-inoculation with two Bradyrhizobium japonicum strains and two commercial arbuscular mycorrhizal fungal (AMF) products. Significant differences were found in the infectivity and effectivity of the microsymbionts. The rhizobial and AMF inoculation generally improved plant production, photosynthetic efficiency and root activity, but this effect depended on the type of symbiotic assotiation. Despite the low infectivity of AMF, inocula containing fungi were more beneficial than those containing only rhizobia. In the Drought Stress (DS) experiment, co-inoculated and control plants were grown in chernozem soil originating from organic farms. Emese was more resistant to drought stress than Aliz and produced a bigger root system. Under DS, the growth parameters of both microbially inoculated cultivars were better than that of control, proving that even drought tolerant genotypes can strengthen their endurance due to inoculation with AMF and nitrogen fixing bacteria. Root electrical capacitance $\left(C_{R}\right)$ showed a highly significant linear correlation with root and shoot dry mass and leaf area. The same root biomass was associated with higher $C_{R}$ in inoculated hosts. As $C_{R}$ method detects the absorptive surface increasing due to inoculation, it may be used to check the efficiency of the microbial treatment.

Keywords: arbuscular mycorrhizal fungi, Bradyrhizobium japonicum, drought stress, functional diversity, root electrical capacitance, soybean, symbiotic compatibility 


\section{INTRODUCTION}

Soybean (Glycine max L. Merr.) is one of the most widely cultivated crops throughout the world under various climates. Future scenarios show that soybean production will expand by $30 \%$ for the coming decade (OECD-FAO, 2018), so optimizing the cultivation of this crop has important economic and political implications.

Achieving this purpose, however, is complicated by the extreme weather conditions caused by global climate change. Crop growth and yield are impaired by both abiotic and biotic stress conditions, of which drought has been identified as the most important factor in limiting the productivity of grain legumes (Farooq et al., 2016). Drought sensitivity coupled with high nutrient demand may seriously restrict soybean yields due to weak development and poor competitiveness against weeds. Therefore, the development of resistant cultivars and site-specific selection from the available genetic resources should be major objectives in any breeding program. The significance of nitrogen-fixing bacteria and arbuscular mycorrhizal fungal (AMF) symbionts is indubitable not only in soybean host nutrition, but also in the alleviation of plant stress caused by adverse soil conditions (Ku et al., 2013).

Nitrogen $(\mathrm{N})$ and phosphorus $(\mathrm{P})$ are critical limiting elements for crop growth (Miller and Cramer, 2004; Menge et al., 2012). Legumes require nitrogen-fixing rhizobial symbiotic partners, mostly Bradyrhizobium japonicum bacteria, to achieve their maximum yield potential. Soils in areas where soybean is not native usually lack these bacteria, e.g., in. in Europe (Albareda et al., 2009), so the microbial inoculation of soybean is essential to provide adequate nitrogen supplies and maximum yields both in conventional agricultural practices and more especially in organic farming.

Leguminous plants are highly dependent also on mycorrhizal fungi (Muleta, 2010), symbionts that can resolve the problem of phosphorus limitation. AM fungi live in a mutualistic symbiosis with $80-90 \%$ of terrestrial plants and form the most ancient and prevalent type of mycorrhizae (Brundrett, 2009). The improved productivity of AM plants and the physiological and biochemical changes caused by AM can result in greater stress resistance in the host (Cameron et al., 2013; Rapparini and Peñuelas, 2014; Domokos et al., 2018). The extraradical hyphal network of AMF provides more effective water and nutrient (especially plant-unavailable phosphorus) uptake for the host plants (Marschner, 1997; Hodge and Storer, 2015; Wahbi et al., 2016; Wang et al., 2016; Balog et al., 2017). Furthermore, the host plants benefit from the special composition of the microbial community in the mycorrhizosphere (Barea, 1997; Artusson et al., 2006).

Recent studies confirm that there is a common genetic basis for plant root endosymbioses with both rhizobia and AM fungi

Abbreviations: AMF, arbuscular mycorrhizal fungi; ARA, acetylene reduction assay; $C_{R}$, root capacitance; DSS, drought stress symptoms; $F_{V} / F_{m}$, maximum quantum efficiency of photosystem II photochemistry; GSI, germination stress index; LA, leaf area; NN, node number; RDW, root dry weight; RMID, relative microbial inoculation dependence; RSR, root shoot ratio; RWC, leaf relative water content; SDW, shoot dry weight; SH, shoot height.
(Denison and Kiers, 2011; Ossler et al., 2015). AMF colonization has an influence on the development and function of rhizobial nodules and vice versa, but the multiple mutualistic effect on the host participating in the rhizobia-AM fungi-legume interaction is very fertilizer-dependent. Numerous publications reported that the co-inoculation of legumes with AMF and rhizobial strains resulted in greater benefits for the plants and symbionts alike, due to a synergistic effect (Bethlenfalvay et al., 1987; Biró et al., 2000; Meghvansi et al., 2008; Wang et al., 2011). Neutral or negative responses to co-inoculation indicated that the advantage of tripartite symbiotic associations depended greatly on the compatibility and susceptibility of the partners (Lisette et al., 2003; Wang et al., 2011). As a principal effect, AM fungi improve nodulation in the legume host by enhancing phosphorus uptake (Ossler et al., 2015). In addition, AMF root colonization leads to changes in the nitrogen transfer, microelement uptake and phytohormone production of the plants, which play an important role in nodulation and nitrogen fixation (Behie and Bidochka, 2014). The multi-factorial evaluation of tripartite functional diversity could provide a theoretical basis for optimizing the application of selected biofertilizers for soybean production.

The varying efficiency of biological nitrogen fixation and fungal colonization both show that the compatibility of the mutualistic partners depends on their genotype. Due to intra- and interspecific variability, several possible partners are in the race for the formation of symbiosis, but the actual outcome of colonization is also influenced by the environmental conditions (Johnson et al., 1997; Kiers et al., 2002; Herrera-Peraza et al., 2011). In general, associations of rhizobia and host plants have narrow specificity during nodule development (Fauvart and Michiels, 2008). The association between the bacteria and the soybean may be host-specific, to such a degree that some rhizobial species nodulate plants only in a certain genus (Neves and Rumjanek, 1997; Appunuu et al., 2008). The variability of bradyrhizobial effectiveness on different soybean varieties was reported by Okereke et al. (2001). In contrast, the AMF-host relationship is not strictly specific; the high intra- and interspecific variability of AM fungi creates great functional diversity (Jakobsen et al., 1992; Munkvold et al., 2004; Cavagnaro et al., 2005).

The great functional diversity and non-host specific association of AM fungi give a chance to produce biofertilizers that can establish fungi-host combinations under diverse environmental conditions. Despite the increasing attention paid to AMF as an advantageous symbiotic partner, a number of difficulties have so far prevented the large-scale application of AMF inoculation (Cely et al., 2016). In low-input organic systems, compatible plant-fungus-rhizobium associations may play a more prominent and critical role in the optimal nutrition of the host plants than in conventional agricultural systems (Gosling et al., 2006; Bhardwaj et al., 2014; Schneider et al., 2015). In organic farming, choosing a suitable cultivar is essential to avoid the damaging effects of environmental stress. The metabolism of drought-tolerant and non-tolerant cultivars has been compared (Purcell et al., 2000; Silvente et al., 2012), but few data are available on cultivars with similar tolerance and on the role of symbionts in endurance. 
Well known, that there are differences in the drought tolerance of the registered soybean cultivars (Bouslama and Schapaugh, 1984; Cseresnyés et al., 2016). It is assumed, that even drought tolerant soybeans benefit from inoculation, but because of the various compatibility cultivars show different responses to microbial treatments. For the rational use of commercial inocula, their efficiency should be checked before application in local soils under different environmental conditions. It is also assumed that AMF will add to drought tolerance more than rhizobium considering the active surfaces. The main objective of the experiments was to show the significance of the compatibility of symbiotic partners in a soybean tripartite inoculation and provide the theoretical basis for the application of commercial products in the soybean field production. To asses the effect of symbioses, it is practical to measure multiple growth, physiological and morphological parameters related to all the partners. In the present study, commercial products containing Bradyrhizobium japonicum and AM fungal inocula were tested for symbiotic effectivity on soybean in different growth media. The host susceptibility to inoculation and the impact of the soil biotic context (belowground interactions) were investigated to reveal their effect on the compatibility of the symbiotic partners. The functionality of the symbiotic partners was also checked in relation to genotypic differences in the soybean cultivars under drought stress.

\section{MATERIALS AND METHODS}

\section{The Sequence of the Experiments}

In the Selection experiment 16 soybean (Glycine max L. Merr.) genotypes of diverse origin (Table 1) were evaluated for drought tolerance by means of polyethylene glycol (PEG) - induced drought stress. The Compatibility pot experiment was than performed to test two bradyrhizobia and two AM fungi (alone and in pairs) by inoculating two selected soybean cultivars grown in pumice to identify the most effective combinations of symbiotic partners. Finally, the Drought Stress pot experiment was performed to study symbiotic efficiency under optimal water supplies and water deficit in soil from organic farms. The test plants, methods of plant cultivation and tests for symbiotic effectiveness were the same in both pot experiments.

\section{Selection Experiment}

The seeds were selected for size homogeneity, surface-sterilized for $0.5 \mathrm{~min}$ in $70 \%(\mathrm{v} / \mathrm{v})$ ethyl alcohol, rinsed and soaked in sterile distilled water. Seed germination was studied in distilled water (control) and in a $25 \mathrm{w} / \mathrm{w} \%$ solution of polyethylene glycol (PEG, Karbowax 6000 Fluka AG) generating an osmotic potential of $-0.82 \mathrm{MPa}$ (Michel and Kaufmann, 1973). For each genotype, four replicates $(n=4)$ of 25 seeds were placed in Petri dish $(\varnothing 9 \mathrm{~cm})$ on a filter paper that covered a piece of cotton wool $(4 \mathrm{~g})$. The dishes were filled with $40 \mathrm{~cm}^{3}$ of distilled water or PEG solution. The seeds were incubated in a dark, temperature-controlled chamber at $25 \pm 1^{\circ} \mathrm{C}$. Seeds were considered germinated when the radicle had reached at least $2 \mathrm{~mm}$ in length. The number of germinated seeds was counted daily. After 6 days, the GSI $_{6}$ was calculated according to Bouslama and Schapaugh (1984). In the Compatibility and Drought Stress experiments the two cultivars with the highest GSI $_{6}$ (Aliz and Emese, indeterminate growth habit, maturity group 0 ) were used as host for the microsymbionts.

\section{Compatibility Experiment}

The Aliz and Emese cultivars were investigated for their compatibility with AM fungi and rhizobial inoculants. Biomass production (shoot and root dry weight; SDW and RDW), LA, photochemical efficiency $\left(\mathrm{F}_{\mathrm{v}} / \mathrm{F}_{\mathrm{m}}\right)$ and root electrical capacitance $\left(C_{R}\right)$ as an indicator of root system activity, were measured in

TABLE 1 | Characteristics of soybean cultivars tested in the germination experiment.

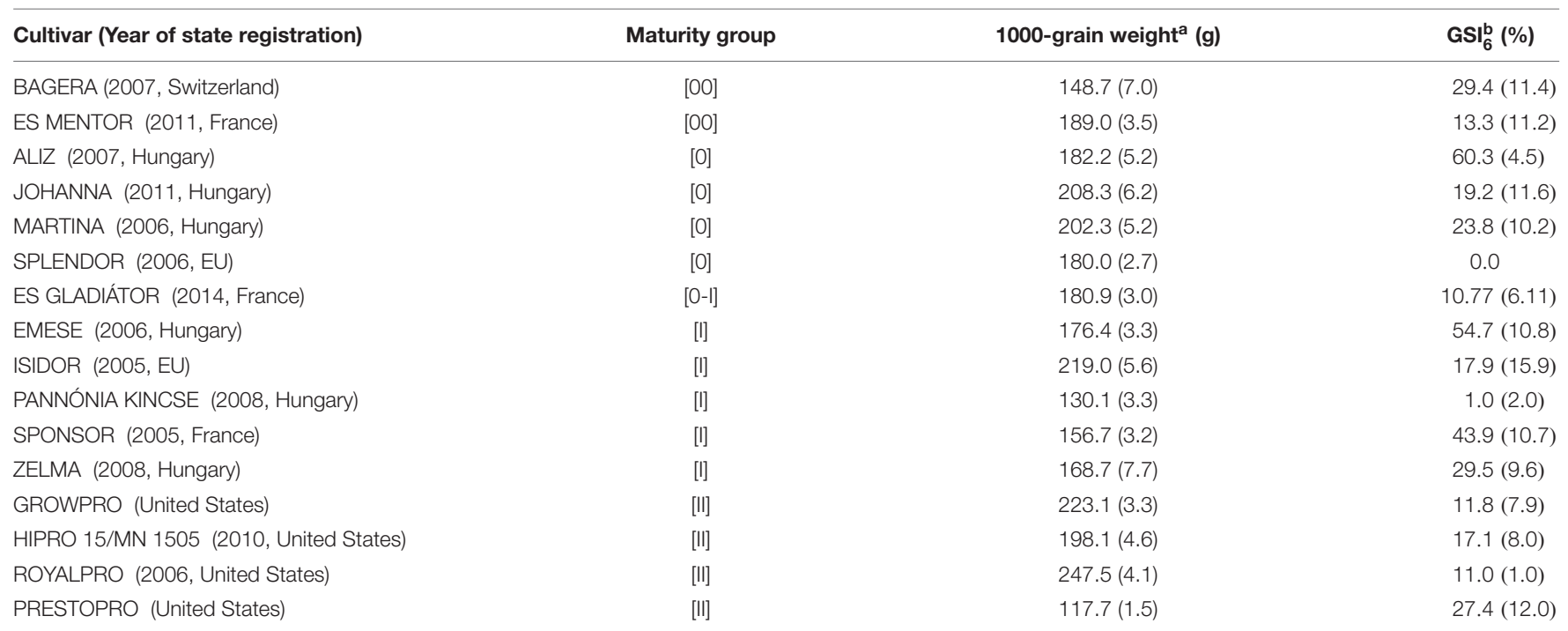

${ }^{a}$ Based upon weighing $5 \times 100$ seeds; standard deviations are given in brackets. ${ }^{b} \mathrm{GSI} 6$, Germination stress index after 6 days of germination. 
the early developmental stages. Root colonization with AMF, nodulating parameters and acetylene reduction were tested to estimate the functionality of the symbiotic partners.

AMF inoculation with a commercial product (either $F_{1}$ or $F_{2}$ ) and rhizobial inoculation with a commercially available soybean inoculum $\left(\mathrm{R}_{1}\right)$ or a Bradyrhizobium japonicum strain $\left(\mathrm{R}_{2}\right)$ were applied as microbial treatments. Control $(\mathrm{C})$ plants were not inoculated.

$F_{1}$ is a 1:1 mixed inoculum of Rhizophagus intraradices (syn. Glomus intraradices) and Funneliformis mosseae (syn. Glomus mosseae) with 50 spores $\mathrm{g}^{-1}$. It is characterized by high organic matter content (20\%), $\mathrm{pH}$ of 6.5-7.0, ammonium lactate (AL)- $\mathrm{K}_{2} \mathrm{O} 8364 \mathrm{mg} \mathrm{kg}^{-1}, \mathrm{AL}-\mathrm{P}_{2} \mathrm{O}_{5} 4987 \mathrm{mg} \mathrm{kg}^{-1}$ and $10^{7}$ colony-forming units of rhizosphere bacteria (CFU $\mathrm{g}^{-1}$ ) in microgranular form (1-2 mm). $\mathrm{F}_{2}$ is an infective propagule mixture of six AMF strains, characterized by $\mathrm{pH}$ of 6.5-7.0, $\mathrm{AL}-\mathrm{K}_{2} \mathrm{O} 6550 \mathrm{mg} \mathrm{kg}^{-1}$ and $\mathrm{AL}-\mathrm{P}_{2} \mathrm{O}_{5} 1402 \mathrm{mg} \mathrm{kg}^{-1}$. It is produced on natural clay carriers and naturally degradable granules of a water-retaining gel. $10 \mathrm{~g} \mathrm{pot}^{-1} \mathrm{AMF}$ inoculum was layered uniformly at a depth of $5 \mathrm{~cm}$ below the seeds in the mycorrhizal treatments.

The $\mathrm{R}_{1}$ microbial treatment was carried out with a peat-based soybean inoculum of Bradyrhizobium japonicum containing $10^{6}$ $\mathrm{CFU} \mathrm{g}^{-1}$. A liquid culture of a $B$. japonicum strain from the strain collection of the Research Institute for Soil Sciences and Agricultural Chemistry was used for the $\mathrm{R}_{2}$ treatment. $\mathrm{R}_{2}$ B. japonicum strain was incubated on yeast extract mannitol agar (YMA) for 5 days (Vincent, 1970). After incubation, one loopful of the culture was suspended in $10 \mathrm{~mL}$ of sterile tap water. $100 \mathrm{~mL}$ of YMB (Yeast Extract Broth) culture medium was inoculated with this bacterial suspension and incubated for 5 days under continuous shaking at $28^{\circ} \mathrm{C}$. In the case of rhizobial inoculation, the seedbed was inoculated with $1 \mathrm{~mL}$ suspension of $\mathrm{R}_{1}(2 \mathrm{~g}$ $200 \mathrm{~mL}^{-1}$ sterile tap water) or $1 \mathrm{~mL}$ liquid culture of $\mathrm{R}_{2}$. Each planting combination was represented by four replicates $(n=4)$.

\section{Drought Stress Experiment}

The Aliz and Emese cultivars were tested for symbiotic effectiveness in chernozem soil treated with the previously selected microbial treatments. Besides the control, both cultivars were exposed to two treatments, co-inoculation with $\mathrm{R}_{1}$ B. japonicum chosen in the Compatibility experiment and $F_{1}$ or $\mathrm{F}_{2} \mathrm{AMF}$ inoculum. Plants growing with different water supplies were investigated in five-five replications $(n=5)$.

\section{Experimental Design and Growth Conditions}

In the Compatibility experiment, the soybean seeds were planted in $721.25 \mathrm{dm}^{3}$ plastic pots containing $1.25 \mathrm{~kg}$ of soil-analog ground pumice (porous vitroclastic perlite) medium with $0.7-1.1 \mathrm{~mm}$ particle size and $\mathrm{pH}_{\mathrm{H} 2 \mathrm{O}}$ 6.5. Two seeds were planted in each pot and thinned to one after emergence. The pumice, which lacks indigenous rhizobia and infective propagules of AM fungi, was treated with AMF or rhizobial inoculums, alone or in combination, except for the controls. The plants were cultivated in a random arrangement in a growth chamber for 65 days with day/night temperature and photoperiod of $26 / 18^{\circ} \mathrm{C}$ and $16 / 8 \mathrm{~h}$ respectively, at a photon flux density of $600 \mu \mathrm{mol} \mathrm{m} \mathrm{m}^{-2} \mathrm{~s}^{-1}$ and relative humidity of $50-70 \%$. Optimal plant nutritional status was maintained by weekly irrigation with $100 \mathrm{ml}$ of modified Hoagland's solution $\left(0.5 \mathrm{M} \mathrm{KH}_{2} \mathrm{PO}_{4}\right)$ per pot.

The Drought Stress experiment was designed to check the results of the Compatibility experiment in organically managed haplic chernozem soil (IUSS Working Group WRB, 2015) that contains an indigenous AMF community. Pre-germinated soybean seeds were transplanted into $3.5 \mathrm{dm}^{3}$ plastic pots filled with $3.9 \mathrm{~kg}$ of soil in five replicates $(n=5)$. The experimental soil, collected in an organic farming system in Martonvásár, Hungary $\left(\mathrm{N} 47^{\circ} 18^{\prime} 41^{\prime \prime}, \mathrm{E} 18^{\circ} 46^{\prime} 48^{\prime \prime}, 109 \mathrm{~m}\right.$ asl.), has a clay loam texture (USDA, $32.8 \%$ sand, $42.2 \%$ silt, $25.0 \%$ clay) with $\mathrm{pH}_{\mathrm{H} 2 \mathrm{O}} 7.69$, $\mathrm{pH}_{\mathrm{KCl}}$ 7.14, ammonium lactate acetate (AL) extractable $\mathrm{P}_{2} \mathrm{O}_{5}$ $371 \mathrm{mg} \mathrm{kg}^{-1}, \mathrm{AL}_{-} \mathrm{K}_{2} \mathrm{O} 402 \mathrm{mg} \mathrm{kg}^{-1}, \mathrm{NH}_{4}{ }^{+}-\mathrm{N} 4.06 \mathrm{mg} \mathrm{kg}^{-1}$, $\mathrm{NO}_{3}{ }^{-}-\mathrm{N} 17.47 \mathrm{mg} \mathrm{kg}^{-1}$, humus $2.93 \%$, and 0.332 and 0.156 $\mathrm{cm}^{3} \mathrm{~cm}^{-3}$ water content at field capacity and permanent wilting point, respectively.

The cultivars were grown for 65 days with the chosen highly effective combinations of microbial partners $\left(\mathrm{F}_{1} \mathrm{R}_{1} ; \mathrm{F}_{2} \mathrm{R}_{1}\right)$ under climatic and light conditions identical to those in the Selection experiment. Half of the plants were watered adequately $(200 \mathrm{ml}$ per pot three times a week) while the others were put through two drought cycles during 23-35 and 40-60 days after planting (DAP). At the beginning of the drought cycles, water was withheld till the soil moisture decreased near to wilting point (requiring 3-6 days, depending on plant size), after which this water status was maintained by daily irrigation during the rest of the drought cycle.

\section{Pre-harvest Investigations}

The effects of non-lethal water deficit during the growth of soybean cultivars prior to the reproductive phase were assessed by recording the number of nodes $(\mathrm{NN})$ on the main stem, measuring the stem height $(\mathrm{SH})$ and the relative water content (RWC) of the leaves, and by examining DSS on the leaves (symptoms of wilting and leaf loss/shedding on a 0-3 scale). Sampling was performed every 7th day from the 14th day after planting (DAP) until the beginning of the reproductive growth stage $\left(R_{1}\right)$. Data representing the functional aspects of the AMF-rhizobia-soybean symbiotic systems were obtained in situ by measuring chlorophyll fluorescence induction and root electrical capacitance $\left(\mathrm{C}_{\mathrm{R}}\right)$.

\section{Chlorophyll Fluorescence Induction}

A FMM Chlorophyll-A fluorometer (Barócsi et al., 2009) was used to measure the fluorescence induction parameters in situ. The internal light source was a $635 \mathrm{~nm}$ laser diode (QL63H5SA, Roithner Lasertechnik GmbH, Wien, Austria) with $20 \mathrm{~mW}$ maximum optical power. Traditional Kautsky induction kinetic curves were detected simultaneously at $690 \mathrm{~nm}$ (red) and $735 \mathrm{~nm}$ (far-red) wavelengths, where Chl-A fluorescence shows two maxima in leaves. Minimal (F0) and maximal fluorescence (Fm) values were detected, after which the light-adapted, steady-state quantum efficiency of photosynthetic electron transport, $\mathrm{F}_{\mathrm{v}} / \mathrm{F}_{\mathrm{m}}=\left(\mathrm{F}_{\mathrm{m}}-\mathrm{F}_{0}\right) / \mathrm{F}_{\mathrm{m}}$, was calculated for both emission 
maxima. The $\mathrm{F}_{\mathrm{v}} / \mathrm{F}_{\mathrm{m}}$ values showed a similar tendency at both wavelengths, so only the results for $690 \mathrm{~nm}$ are shown. The $\mathrm{F}_{\mathrm{v}} / \mathrm{F}_{\mathrm{m}}$ data were measured on all the plants on 63 DAP.

\section{Root Electrical Capacitance $\left(\mathrm{C}_{\mathrm{R}}\right)$ Measurement}

The extension and activity of the root system (rhizosphere) was assessed simply in situ by $C_{R}$ measurement (Chloupek, 1972; Cseresnyés et al., 2016). When an alternating current passes through the root tissue, charge accumulation, i.e., polarization, occurs. The amount of electric charge stored by the root system can be expressed as electrical capacitance (in nanofarads) which is proportional to the active root surface area. The method is only valid for the comparison of plants of the same species grown in the same substrate, at the same moisture level (Chloupek et al., 2010). $C_{R}$ measurements were carried out on all the plants on DAP 64 (before harvest and after the second drought stress period in the Drought Stress experiment) using a GW-8101G LCR instrument (GW Instek Co., Ltd., Taiwan) at $1 \mathrm{kHz}$ frequency with $1 \mathrm{~V}$ terminal voltage. One terminal of the instrument was connected to the plant stem with a spring tension clamp fixed $10 \mathrm{~mm}$ above the substrate level, while the second was grounded by a stainless steel rod (6 $\mathrm{mm}$ ID, $15 \mathrm{~cm}$ long) inserted into the substrate. Electrocardiograph paste (Vascotasin ${ }^{\circledR}$; Spark Promotions Co., Ltd., Budapest, Hungary) was smeared around the stem to maintain electrical contact, and the substrate was irrigated to field capacity before measurement.

\section{Leaf Relative Water Content (RWC)}

In the Drought Stress experiment, the relative water content (RWC) of the leaves was measured during drought exposure on DAP 22 and DAP 63 (González and González-Vilar, 2007).

\section{Post-harvest Measurements}

Both the inoculated and control soybeans were harvested and sampled for microbial investigations after 65 days of cultivation (R1, R2 flowering stage and R3 green pod formation) (Ohyama et al., 2013). LA was measured using image processing. In both experiments, SDW and RDW were determined after drying the samples at $80^{\circ} \mathrm{C}$ for $48 \mathrm{~h}$. The susceptibility to symbiotic associations and the dependence of soybean cultivars on microbial treatments were characterized by the index of RMID. RMID is an extension of the relative field mycorrhizal dependence (RFMD) index (Plenchette et al., 1983), taking into consideration all symbionts rather than just AMF, and is defined as $\mathrm{RMID}=100 *[$ (dry weight of inoculated plant)-(dry weight of non-inoculated plant)]/dry weight of inoculated plant.

\section{Quantification of AMF Root Colonization, Nodulation and Functionality of Rhizobia}

After harvest, the soybean response to rhizobial inoculation was characterized by a number representing the density of nodules found on the primary roots and lateral root zones.

The nitrogenase enzyme activity of the nodules was measured by means of ARA (Hardy et al., 1968). After removing them from the pots, the 65-day-old plants were carefully washed, then the whole, nodulated roots were placed in a $500 \mathrm{ml}$ glass bottle capped with a rubber septum. After adding $50 \mathrm{~cm}^{3}$ of acetylene gas $\left(\mathrm{C}_{2} \mathrm{H}_{2},>99.95 \%\right.$ purity, Lindegas $)$ to the bottle, the roots were incubated for $30 \mathrm{~min}$ at room temperature $\left(22^{\circ} \mathrm{C}\right)$. A gas sample $(500 \mu \mathrm{l})$ was removed using a gas-tight syringe and analyzed on a gas chromatograph (GC 8000, FISONS Instruments) with the following specifications: flame ionization detector (FID) and Porapak T column to separate ethylene from acetylene, carrier gas $\mathrm{N}_{2}=175 \mathrm{kPa}$, hydrogen at $50 \mathrm{kPa}$, air at $80 \mathrm{kPa}$, injector temperature $100^{\circ} \mathrm{C}$, oven temperature $80^{\circ} \mathrm{C}$, isotherm, detector temperature $150^{\circ} \mathrm{C}$. The area under the peaks was evaluated with Chrom-Card software and a standard of 10 ppm ethylene $\left(\mathrm{C}_{2} \mathrm{H}_{4}\right)$ in $\mathrm{N}_{2}$ (Scotty 14 , Supelco) was used for calibration.

After ARA, the roots were randomly sampled for AMF root colonization measurement performed after staining the separated root ( $\leq 1 \mathrm{~mm}$ indiameter) sub-samples with lactic acid-aniline blue according to Phillips and Hayman (1970). AMF colonization was estimated using a BX51 microscope (40-200X; Olympus Corp., Tokyo, Japan). The frequency (F\%), the intensity of colonization $(\mathrm{M} \%)$ and the arbusculum richness $(\mathrm{A} \%)$ in the roots were calculated using a five-class system (Trouvelot et al., 1986) after observing 30 fine root segments, each $1 \mathrm{~cm}$ in length.

\section{Concentration of Nitrogen (N), Phosphorus $(\mathrm{P})$ and Potassium (K) in Leaves}

The $\mathrm{N}(\%), \mathrm{P}$ and $\mathrm{K}\left(\mathrm{mg} \mathrm{kg}^{-1}\right)$ concentrations of the plants were measured after harvest. The $\mathrm{P}$ and $\mathrm{K}$ macroelement concentrations of the plants were assessed after wet digestion of air-dried plant samples with cc. $\mathrm{HNO}_{3}+\mathrm{cc} . \mathrm{H}_{2} \mathrm{O}_{2}$. The nitrogen content in the leaves was determined by the Kjeldahl method (Kjeldahl, 1883) after digesting the samples in sulfuric acid (cc. $\mathrm{H}_{2} \mathrm{SO}_{4}$ ). The leaf element contents were measured with an ICP-AES instrument (Jobin-Yvon, ULTIMA2).

\section{Statistical Analysis}

Results were analyzed using two-way ANOVA or Kruskal-Wallis non-parametric test if the prerequisites of ANOVA did not fulfill. Bartlett test of homogeneity of variance and Shapiro-Wilk normality test with model residuals were carried out before ANOVA. Post hoc tests were also carried out: LSD (least significant differences) values were calculated after ANOVA analysis, while a pairwise $t$-test with the Holm method was applied after the Kruskal-Wallis test. The comparisons between means were performed at the significance level of $p<0.05$. The relationship between $C_{R}$ and RDW or LA were evaluated using simple regression analysis $(p<0.05$ for each treatment).

\section{RESULTS}

\section{Selection Experiment}

The negative osmotic potential significantly decreased seed germination (Table 1). The PEG solution retarded germ development, to the greatest extent for the cultivar Splendor. The $\mathrm{GSI}_{6}$ values ranged from $0.0 \%$ (Splendor) to $60.3 \%$ (Aliz). Cultivars Aliz and Emese had the highest GSI $_{6}$ values, so these were assumed to have high drought stress tolerance in the early stages of plant development. There was no relationship between 
the 1000-grain weight or maturity group of the cultivars and the GSI levels.

\section{Compatibility Experiment}

In the Compatibility experiment all the AMF and dual inoculations resulted in higher SDW and RDW (Figures 1A,C), stem length and number of nodes (data not shown), especially in the $\mathrm{F}_{1}$ AMF treatments. The biomass production of AM plants was significantly higher (by 50-70\%) than that of the controls or plants inoculated only with rhizobium. No significant differences in SDW and RDW were found between the soybean cultivars, though the SDW of Aliz was slightly higher than that of Emese. Aliz grew taller and were spindlier. The LA of the differentially inoculated soybean plants showed a tendency similar to their shoot biomass and dry weights (Figure 1B), except that Emese had higher LA than Aliz. No AMF structures were detected in the control or rhizobium inoculated plants $\left(\mathrm{C}\right.$ and $\mathrm{R}_{1,2}$ ). Microscopic examination of the harvested roots showed a low frequency (F\%) of fungal colonization in mycorrhizal plants irrespective of the AMF products.

A comparison of $F_{1}$ and $F_{2}$ showed that the former caused a greater increase in host growth, while the latter resulted in a higher colonization rate $\left[\mathrm{F}_{1} \max (\mathrm{F} \%=1.67) ; \mathrm{F}_{2} \max (\mathrm{F} \%=19.84)\right]$. AMF root colonization decreased in plants co-inoculated with both rhizobial and AMF products. No significant differences in AMF infectivity were found for the different host plant cultivars.

Bradyrhizobium inoculation resulted in intensive nodule formation on both the main root and lateral roots in all cases (100-150 nodules plant $\left.{ }^{-1}\right)$, but there were no significant differences between either the rhizobial treatments or the soybean cultivars. The ARA revealed that $R_{1}$ had 2-5 times higher nitrogen-fixing capability $\left(\mathrm{R}_{1}: 685 \mathrm{~nm} \mathrm{C}_{2} \mathrm{H}_{4} \mathrm{~h}^{-1}\right.$ pot $^{-1} ; \mathrm{F}_{1} \mathrm{R}_{1}$ : $633 \mathrm{~nm} \mathrm{C} \mathrm{C}_{2} \mathrm{H}_{4} \mathrm{~h}^{-1}$ pot $^{-1} ; \mathrm{F}_{2} \mathrm{R}_{1}: 623 \mathrm{~nm} \mathrm{C}_{2} \mathrm{H}_{4} \mathrm{~h}^{-1}$ pot $^{-1}$ ) than $\mathrm{R}_{2}\left(\mathrm{R}_{2}: 252 \mathrm{~nm} \mathrm{C} \mathrm{H}_{4} \mathrm{~h}^{-1}\right.$ pot $^{-1} ; \mathrm{F}_{1} \mathrm{R}_{2}: 144 \mathrm{~nm} \mathrm{C} \mathrm{C}_{4} \mathrm{~h}^{-1}$ pot $^{-1} ; \mathrm{F}_{2} \mathrm{R}_{2}: 199 \mathrm{~nm} \mathrm{C}_{2} \mathrm{H}_{4} \mathrm{~h}^{-1}$ pot $\left.^{-1} ; \mathrm{LSD}=198, P<0.05\right)$. There were no significant differences in the specific activity of the nitrogenase in the rhizobium-inoculated cultivars. The RMID of rhizobium- inoculated soybeans $\left(\mathrm{R}_{1,2}\right)$ was lower than that of AMF- or co-inoculated plants, and Emese showed higher dependence than Aliz (except in $F_{2} R_{2}$ ) in well-watered pumice (data not shown).

The $\mathrm{N}$ content of plants treated only with rhizobium $\left(\mathrm{R}_{1} ; \mathrm{R}_{2}\right.$ in the case of Aliz) was significantly higher than that of control (C) and AMF-inoculated $\left(\mathrm{F}_{1} ; \mathrm{F}_{2} ; \mathrm{F}_{1} \mathrm{R}_{1} ; \mathrm{F}_{1} \mathrm{R}_{2} ; \mathrm{F}_{2} \mathrm{R}_{1} ; \mathrm{F}_{2} \mathrm{R}_{2}\right)$ hosts (Table 2). The leaf $\mathrm{N}$ content of Aliz was significantly higher, than that of Emese in the $F_{1}, R_{2}, F_{1} R_{1}$ and $F_{2} R_{2}$ treatments. The $P$ concentration was generally higher in the leaves of Emese, except for the $F_{1}$ treatment where a significant increment occurred in Aliz (Table 3).

Root electrical capacitance $\left(C_{R}\right)$ was the highest in AMF-treated plants (Figure 1D) for both Emese and Aliz. Significant differences in $C_{R}$ were found between the mycorrhizal and non-mycorrhizal $\left(C, R_{1}, R_{2}\right)$ plants. Rhizobium treatment caused a lower, but still significant increase in $C_{R}$.

The photochemical efficiency $\left(\mathrm{F}_{\mathrm{v}} / \mathrm{F}_{\mathrm{m}}\right)$ differed only slightly among the microbial treatments. $R_{1}, F_{1} R_{1}$ and $F_{1} R_{2}$ inoculation resulted in significantly higher $\mathrm{F}_{\mathrm{v}} / \mathrm{F}_{\mathrm{m}}$ ratios than the control (C: $0.827 ; \mathrm{R}_{1}: 0.839 ; \mathrm{F}_{1} \mathrm{R}_{1,2}: 0.840,0.843$ respectively; $\mathrm{LSD}_{5 \%}=0.011$ ). Photochemical efficiency also differed between the two varieties (Aliz: 0.836; Emese 0.827; $\mathrm{LSD}_{5 \%}=0.006$ ).

\section{Drought Stress Experiment}

Microbial inoculation caused a significant increment in SDW, LA, RDW (Figures 2A-C) and NN (except in $\mathrm{F}_{1} \mathrm{R}_{1}$ ) (Figure 2D) under both well-watered (WW) and drought stress (DS) conditions. The beneficial efficiency of the $\mathrm{F}_{1}$ was mostly higher than that of $\mathrm{F}_{2}$ (Figure 2). The microsymbionts induced a more than two-fold increase in LA (WW: 126-128\%; DS: 113-115\%) (Figure 2B). The LA of Emese was generally higher than that of Aliz. RDW was enhanced by $41-58 \%$ (WW) and 24-30\% (DS) by co-inoculation (Figure 2C). Greater changes were observed in shoot than in root biomass production: inoculation increased SDW by $60-69 \%$ (WW) and $54 \%$ (DS).

The RSR values of microbially treated and control plants were statistically similar under WW conditions (Figure 2E).

Shoot dry weight decreased by $41 \%$ in the control and by $41-45 \%$ in the co-inoculated plants (Figure 2A). LA was $40 \%$ smaller in the control and $44 \%$ smaller in the co-inoculated plants (Figure 2B), while RDW was reduced by $22 \%$ in the control and by $31-36 \%$ in the co-inoculated plants (Figure 2C). NN also decreased significantly under drought stress (Figure 2D). SH was 21-24\% lower after inoculation in the case of DS.

Combined inoculation with AM fungi and rhizobia was significantly more beneficial for Emese than for Aliz, as shown by differences in various plant growth parameters (LA: 10\%, RSR: 15\%) (Figures 2B,E). By contrast, the SDW of Aliz was higher than that of Emese. DS induced a greater decrease in SDW (35\% Emese and 45\% Aliz) than in RDW (18\% Emese and $40 \%$ Aliz). No differences were found between the effects of $F_{1}$ and $F_{2}$ AMF inocula on plant growth. The drought-induced decline in LA ranged from 36\% (Emese $\left.\mathrm{F}_{2} \mathrm{R}\right)$ to $50 \%$ (Aliz $\mathrm{F}_{2} \mathrm{R}$ ). Water deficit increased the RSR values in all the treatments and led to significant differences between the RSR values of inoculated and control plants, which were absent under WW conditions. Cultivar Emese exhibited significantly higher RSR than Aliz (Figure 2E). The growth parameters of $F_{1}$ and $F_{2}$ treated plants were statistically similar under DS.

There were no significant differences in RWC between microbially treated and control plants under WW conditions, irrespective of the cultivar (Figure 3A). The exposure of plants to drought led to a noticeable decrease in leaf RWC from 90.4-93.4\% to $44.7-78.2 \%$ with significantly lower values for inoculated cultivars than for non-inoculated ones. Cultivar Aliz generally had higher RWC values in the vegetative phenophase, especially when inoculated before DS.

No differences were found in the DSS of the two cultivars in any treatment, though plants inoculated with $\mathrm{F}_{1}$ exhibited pronounced wilting symptoms (Figure 3B).

Fluorescein diacetate (FDA) hydrolysis revealed that the activity of soil microbes was significantly inhibited by DS in 


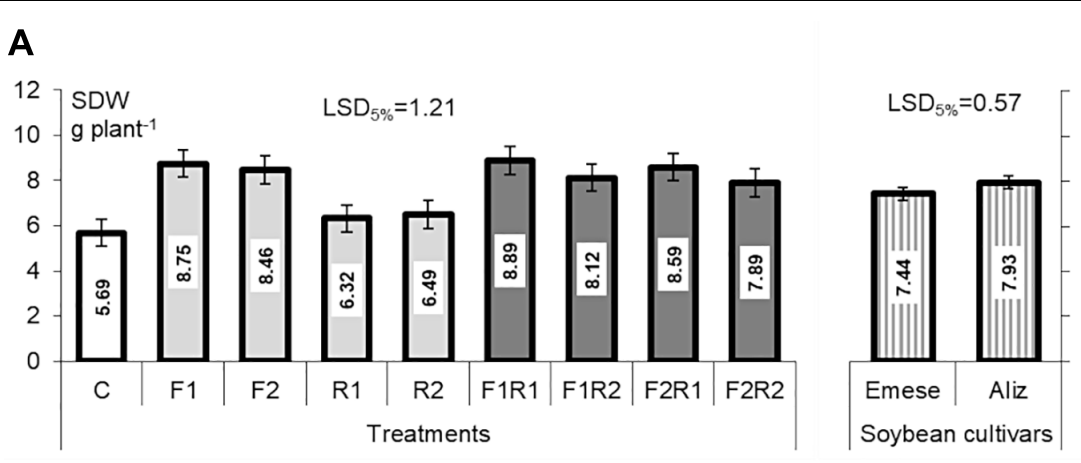

\section{B}
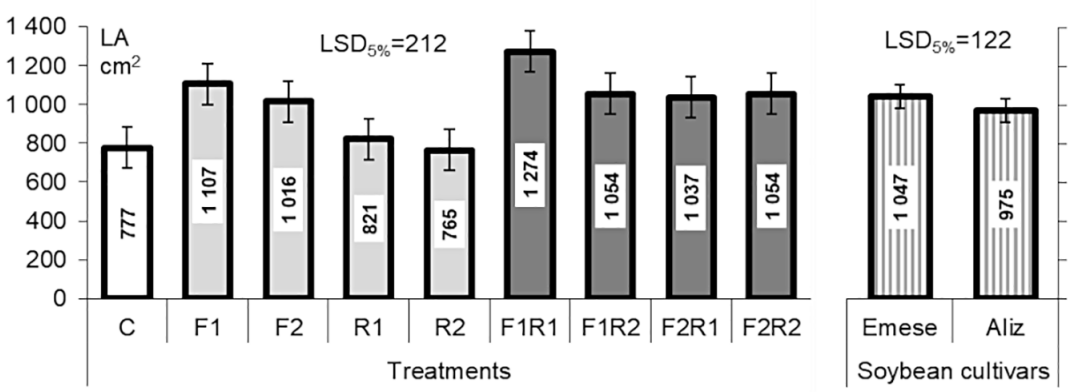

C
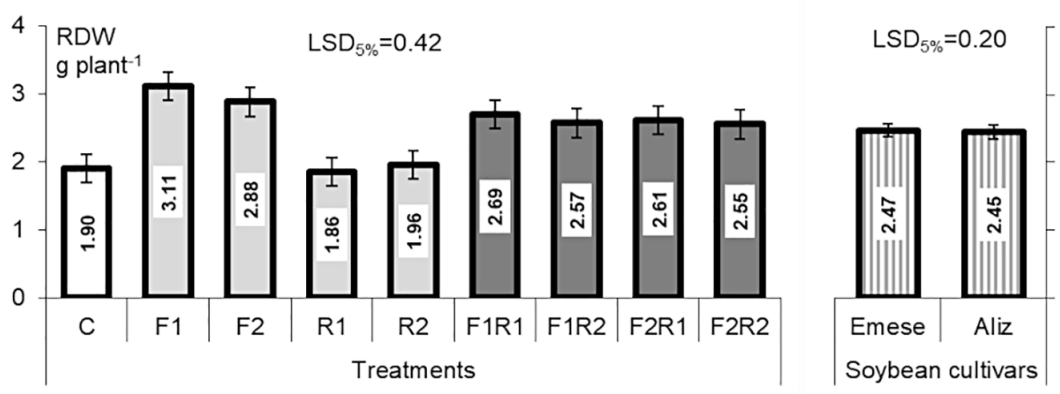

D
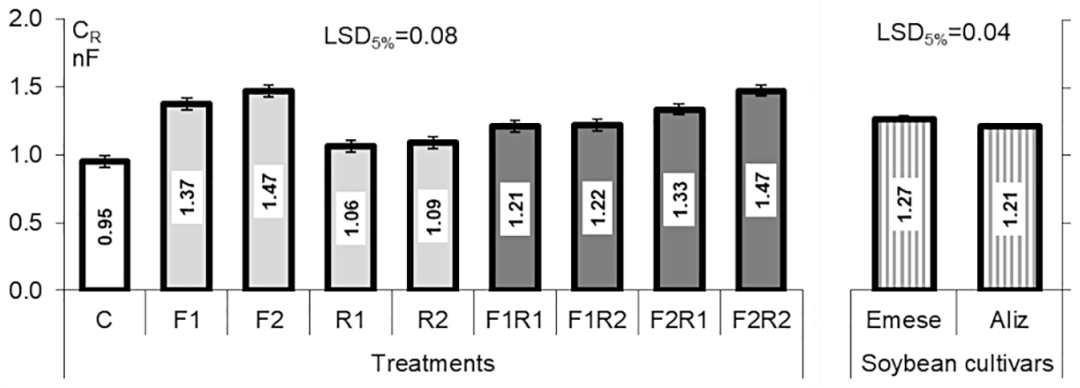

FIGURE 1 | (A) Shoot dry weight (SDW), (B) leaf area (LA), (C) root dry weight (RDW), and (D) root electrical capacitance (C $\mathrm{R}_{\mathrm{R}}$ ) of Emese and Aliz soybean cultivars in the Compatibility experiment. Mean values of the microbial inoculation treatments (left side in the Figure: $C$, control plants; $R_{1}$ and $R_{2}$ rhizobia; $F_{1}$ and $F_{2}$ AM fungal products) and mean values of soybean cultivars (right side in the Figure). Error bars represent $\operatorname{LSD}(n=4 ; p<0.05)$.

all the treatments. No significant effect of co-inoculation was observed for either WW (28.9-30.8 $\mu \mathrm{g} \mathrm{Fl} \mathrm{g}^{-1} \mathrm{~h}^{-1}$; $\mathrm{LSD}=4.2$, $P<0.05)$ or DS $\left(20.0-22.8 \mu \mathrm{g} \mathrm{Fl} \mathrm{g}^{-1} \mathrm{~h}^{-1}\right)$. The FDA activity was also independent of the cultivar (Emese $24.2 \mu \mathrm{g} \mathrm{Fl} \mathrm{g}^{-1} \mathrm{~h}^{-1}$; Aliz $\left.26.5 \mu \mathrm{g} \mathrm{Fl} \mathrm{g}^{-1} \mathrm{~h}^{-1} ; \mathrm{LSD}=2.4, P<0.05\right)$ in both watering regimes.
The number of nodules on the roots of co-inoculated plants was much higher than on non-inoculated, control plants. Nodulation was independent of both the application of mycorrhizal fungi and the cultivar under both watering regimes. 
TABLE 2 | Nitrogen (N) content (\%) of soybean leaves at the end of the Compatibility experiment.

\begin{tabular}{lccc}
\hline $\mathbf{N}(\%)$ & Cultivar: Emese & Cultivar: Aliz & LSD $_{\mathbf{5} \% \mathbf{0 . 3 0}}$ \\
\hline $\mathrm{C}$ & $2.48 \pm 0.44$ & $2.50 \pm 0.34$ & 2.49 \\
$\mathrm{~F}_{1}$ & $2.24 \pm 0.51$ & $2.69 \pm 0.29$ & 2.47 \\
$\mathrm{~F}_{2}$ & $2.27 \pm 0.21$ & $2.22 \pm 0.25$ & 2.25 \\
$\mathrm{R}_{1}$ & $2.96 \pm 0.19$ & $2.85 \pm 0.12$ & 2.91 \\
$\mathrm{R}_{2}$ & $2.45 \pm 0.03$ & $3.09 \pm 0.11$ & 2.77 \\
$\mathrm{~F}_{1} \mathrm{R}_{1}$ & $2.47 \pm 0.15$ & $2.94 \pm 0.35$ & 2.71 \\
$\mathrm{~F}_{\mathbf{1}} \mathrm{R}_{2}$ & $2.69 \pm 0.11$ & $2.79 \pm 0.39$ & 2.74 \\
$\mathrm{~F}_{2} \mathrm{R}_{\mathbf{1}}$ & $2.70 \pm 0.39$ & $2.51 \pm 0.43$ & 2.61 \\
$\mathrm{~F}_{2} \mathrm{R}_{2}$ & $2.47 \pm 0.29$ & $2.73 \pm 0.24$ & 2.60 \\
\hline LSD $_{\mathbf{5} \%} \mathbf{0 . 1 4}$ & 2.53 & 2.70 & Mean values
\end{tabular}

Means and standard errors of four replicates. Two-way analysis of variance was performed. $L S D_{5 \%}$ values indicate the least significant difference at the $p=0.05$ level. Microbial treatments: $C$, non-inoculated control plants; $F_{1,2}$, commercial AMF inocula; $R_{1,2}$, Bradyrhizobium japonicum inocula; Soybean cultivars: Aliz and Emese.

TABLE 3 | Phosphorus (P) concentration $\left(\mathrm{mg} \mathrm{kg}^{-1}\right)$ of soybean leaves at the end of the Compatibility experiment.

\begin{tabular}{lccc}
\hline $\mathbf{P}\left(\mathbf{~ m g ~ k g}^{\mathbf{- 1}}\right)$ & Cultivar: Emese & Cultivar: Aliz & LSD $_{\mathbf{5 \%}} \mathbf{2 9 8}$ \\
\hline $\mathrm{C}$ & $1629 \pm 126$ & $1593 \pm 245$ & 1611 \\
$\mathrm{~F}_{1}$ & $1889 \pm 307$ & $1907 \pm 361$ & 1898 \\
$\mathrm{~F}_{2}$ & $1599 \pm 326$ & $1325 \pm 343$ & 1462 \\
$\mathrm{R}_{1}$ & $1825 \pm 138$ & $1466 \pm 137$ & 1645 \\
$\mathrm{R}_{2}$ & $1465 \pm 137$ & $1512 \pm 188$ & 1488 \\
$\mathrm{~F}_{1} \mathrm{R}_{1}$ & $1649 \pm 320$ & $1634 \pm 227$ & 1641 \\
$\mathrm{~F}_{1} \mathrm{R}_{2}$ & $1703 \pm 206$ & $1644 \pm 513$ & 1674 \\
$\mathrm{~F}_{2} \mathrm{R}_{1}$ & $1522 \pm 272$ & $1259 \pm 343$ & 1390 \\
$\mathrm{~F}_{2} \mathrm{R}_{2}$ & $1365 \pm 373$ & $1396 \pm 443$ & 1381 \\
\hline
\end{tabular}

\begin{tabular}{llll}
\hline LSD $_{\mathbf{5}} \mathbf{1 4 1}$ & 1627 & 1526 & Mean values
\end{tabular}

Means and standard errors of four replicates. Two-way analysis of variance was performed. $L S D_{5 \%}$ values indicate the least significant difference at the $p=0.05$ level. Microbial treatments: $C$, non-inoculated control plants; $F_{1,2}$, commercial AMF inocula; $R_{1,2}$, Bradyrhizobium japonicum inocula; Soybean cultivars: Aliz and Emese.

The intensity of colonization (M\%) in the roots ranged from $35.2 \%$ to $60.8 \%$ in $\mathrm{WW}$ soil, with the lowest rate for $\mathrm{F}_{2}$ (Figure 3C). The $\mathrm{M} \%$ of roots colonized by indigenous AMF exhibited a $9 \%$ increase in response to DS, while those colonized by AMF species from commercial products had suppressed or unchanged infectivity. Indigenous AMF alone generated a higher colonization in roots than it was observed after the inoculation with $\mathrm{F}_{1}$ or $\mathrm{F}_{2}$. The intensity of AMF colonization in the roots was slightly higher for Aliz than for Emese. The characteristics of and changes in arbusculum richness (A\%) were similar to those of $\mathrm{M} \%$, again proving the better natural infectivity and responsiveness of Aliz. The increment in A\% caused by DS was significant (data not shown). The RMID values for mycorrhizal and rhizobial treatments of the cultivars were greater under WW than under DS conditions. Under WW conditions, Emese had slightly higher susceptibility to microbial inoculation than Aliz, but DS inverted this relationship.

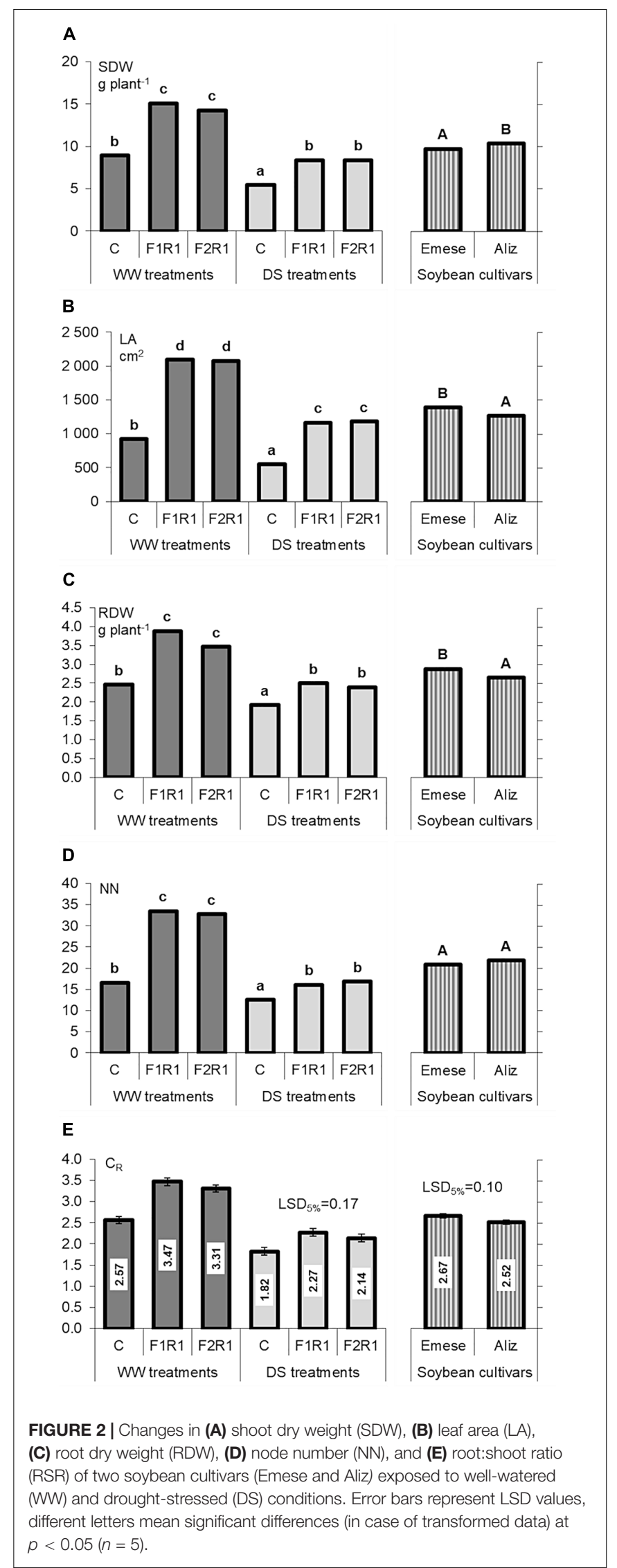




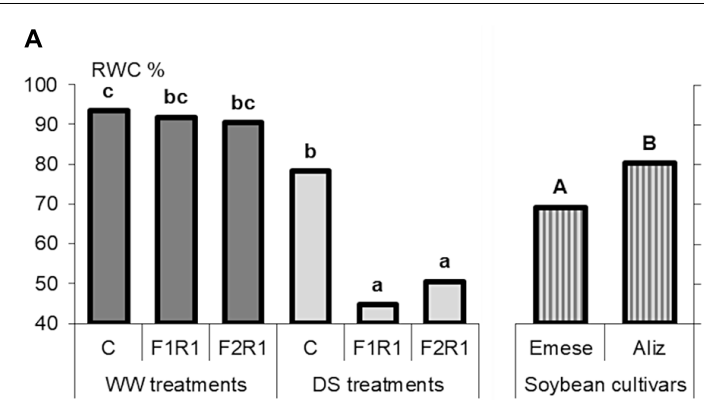$$
\text { B }
$$$$
3 \text { ] DSS }
$$

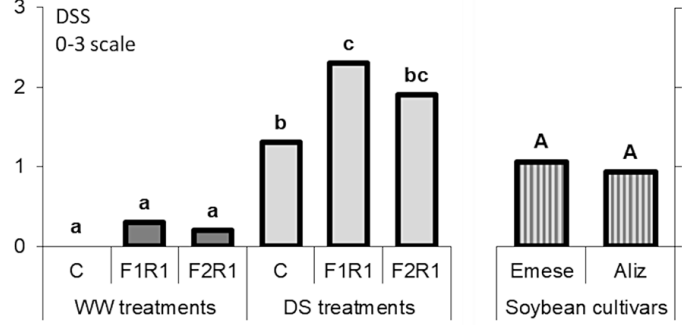

c
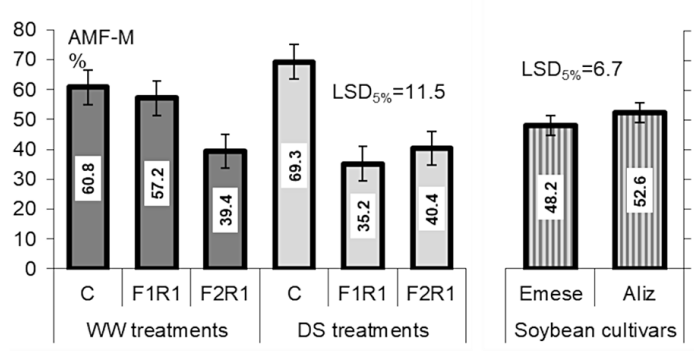

D

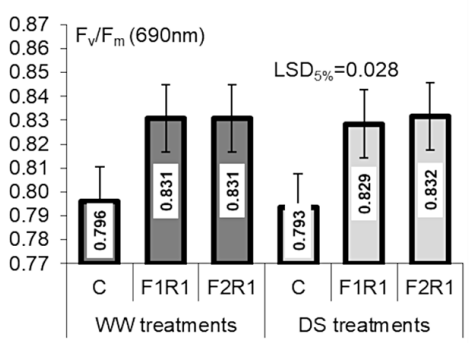

$\mathrm{LSD}_{5 \%}=0.016$

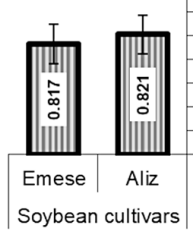

E

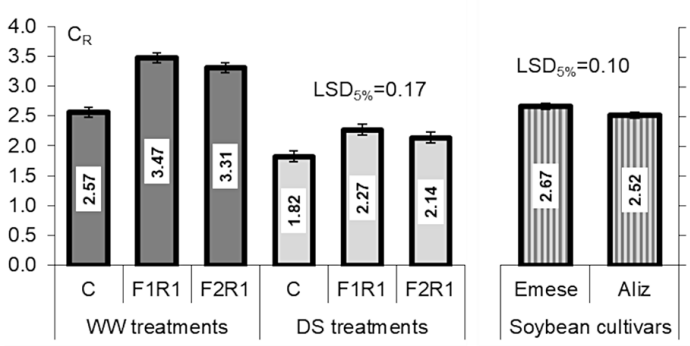

FIGURE 3 | (A) Leaf relative water content (RWC), (B) drought-induced stress symptoms (DSS), (C) AMF colonization (M\%), (D) chlorophyll-a fluorescence $\left(F_{v} / F_{m}\right)$ and $(E)$ root electrical capacitance $\left(C_{R}\right)$ of control $(C)$ and co-inoculated $\left(F_{1} R_{1}, F_{2} R_{2}\right)$ soybeans for different cultivars (Emese, Aliz) under well-watered (WW) and drought-stressed (DS) conditions. Error bars represent LSD values, different letters mean significant differences (in case of pairwise $t$-test) at $p<0.05$.
$\mathrm{F}_{\mathrm{v}} / \mathrm{F}_{\mathrm{m}}$ values were increased by dual inoculation under both water regimes (Figure 3D). Drought did not significantly affect the photosynthetic activity, and the quantum efficiency of PSII was independent of the cultivar.

Microbial inoculation significantly enhanced the $C_{R}$ values of the cultivars, irrespectively of watering, particularly in the case of Emese (Figure 3E). The effect of $F_{1}$ on $C_{R}$ (36\% for Aliz, $34 \%$ for Emese under WW; $21 \%$ for Aliz and 28\% at Emese under DS) was greater than that of $\mathrm{F}_{2}$ (26\% for Aliz, $32 \%$ for Emese under WW; $14 \%$ for Aliz and 20\% for Emese under DS) (Figure 3D). $C_{R}$ decreased significantly in response to DS, to a greater extent for Aliz (31-37\%, as a percentage of WW) than for Emese (27-33\%). Cultivar Emese exhibited significantly higher $\mathrm{C}_{\mathrm{R}}$ than Aliz at the end of the experiment. A good linear correlation $(P<0.01)$ was obtained between $\mathrm{C}_{\mathrm{R}}$ and both SDW $\left(R^{2}=0.829\right)$ and LA $\left(R^{2}=0.716\right)$ by pooling the data of the six plant groups. Strong linear correlations were found between both $\mathrm{C}_{\mathrm{R}}$ and RDW and $\mathrm{C}_{\mathrm{R}}$ and LA (Aliz $R^{2}=0.672$; Emese $R^{2}=0.758$ ). Figures $4 A, B$ illustrate an increase in $C_{R}$ due to inoculation and a decrease due to drought stress. Regression analysis demonstrated linear correlations between $\mathrm{C}_{\mathrm{R}}$ and $\mathrm{RDW}$ for each treatment. The same root biomass was associated with higher $C_{R}$ in inoculated treatments and with lower values in the case of drought stress (Figure 4B).

The beneficial effect of rhizobial nodulation on the leaf nitrogen concentration was detected, as in the Selection

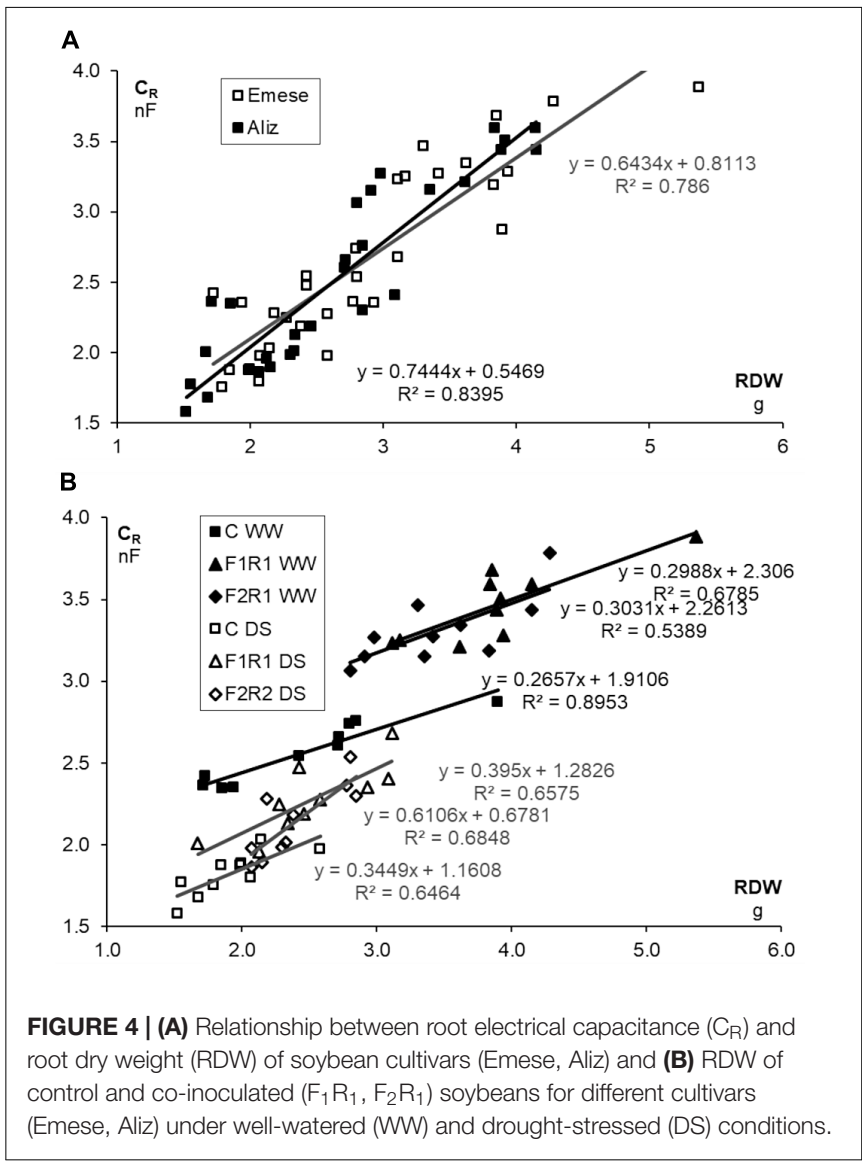


experiment. The leaf $\mathrm{N}$ percentage of inoculated plants significantly exceeded the controls under both WW and DS conditions (Table 4), but no significant differences were found either between the cultivars or between the microbial treatments. The leaf $\mathrm{P}$ concentration was decreased by drought and by inoculation under WW conditions, although DS led to higher leaf $\mathrm{P}$ concentration in inoculated plants compared to controls (Table 5). The total $\mathrm{P}$ content in the leaves was significantly higher in inoculated plants than in control plants. The $\mathrm{P}$ concentrations in Emese were greater than in Aliz.

\section{DISCUSSION}

For the future of mycorrhizal biotechnology and industry, it is crucial to incorporate the scientific knowledge derived from fundamental and applied research into the innovation of microbial inoculants (Vosátka et al., 2012). Although various commercial microbial products are already in use, few data have been published on their effect on plant development, nutrition and yield under controlled environmental conditions (Bona et al., 2016). Most studies have been primarily focused on the

TABLE 4 | Nitrogen (N) content (\%) of soybean leaves at the end of the Drought stress experiment.

\begin{tabular}{lcccc}
\hline $\mathbf{N}$ (\%) & & Cultivar: Emese & Cultivar: Aliz & LSD $_{\mathbf{5} \%} \mathbf{0 . 3 6}$ \\
\hline WW & $C$ & $1.33 \pm 0.33$ & $1.51 \pm 0.81$ & 1.42 \\
& $F_{1} R_{1}$ & $3.12 \pm 0.27$ & $2.96 \pm 0.24$ & 3.04 \\
& $F_{2} R_{1}$ & $3.08 \pm 0.26$ & $3.27 \pm 0.32$ & 3.18 \\
DS & $C$ & $1.49 \pm 0.39$ & $1.20 \pm 0.19$ & 1.34 \\
& $F_{1} R_{1}$ & $3.04 \pm 0.23$ & $2.93 \pm 0.47$ & 2.99 \\
& $F_{2} R_{1}$ & $3.06 \pm 0.26$ & $3.10 \pm 0.54$ & 3.08 \\
\hline LSD $_{\mathbf{5} \%} \mathbf{0 . 2 1}$ & 2.52 & 2.49 & Mean values
\end{tabular}

Means and standard errors of five replicates. Two way-analysis of variance was performed. $L S D_{5 \%}$ values indicate the least significant difference at the $p=0.05$ level. Microbial treatments: $C$, non-inoculated control plants; $F_{1,2}$, commercial AMF inocula; $R_{1,2}$, Bradyrhizobium japonicum inocula; Soybean cultivars: Aliz and Emese; WW, well-watered conditions; DS, drought stress conditions.

TABLE 5 | Phosphorus (P) concentration $\left(\mathrm{mg} \mathrm{kg}^{-1}\right)$ of soybean leaves at the end of Drought stress experiment.

\begin{tabular}{ccccc}
\hline $\left.\mathbf{P} \mathbf{( m g ~ k g}^{-\mathbf{1}}\right)$ & Cultivar: Emese & Cultivar: Aliz & LSD $_{\mathbf{5} \%} \mathbf{3 3 3}$ \\
\hline WW & $C$ & $3871 \pm 780$ & $3155 \pm 345$ & 3513 \\
& $F_{1} R_{1}$ & $2693 \pm 350$ & $2300 \pm 126$ & 2496 \\
& $F_{2} R_{1}$ & $2523 \pm 131$ & $2360 \pm 118$ & 2441 \\
DS & $C$ & $3091 \pm 334$ & $3342 \pm 616$ & 3217 \\
& $F_{1} R_{1}$ & $2744 \pm 344$ & $2714 \pm 271$ & 2729 \\
& $F_{2} R_{1}$ & $2968 \pm 103$ & $2682 \pm 226$ & 2825 \\
\hline LSD $_{\mathbf{5} \% \mathbf{~} \mathbf{1 9 2}}$ & 2981 & 2759 & Mean values
\end{tabular}

Means and standard errors of five replicates. Two-way analysis of variance was performed. $L S D_{5 \%}$ values indicate the least significant difference at the $p=0.05$ level. Microbial treatments: $C$, non-inoculated control plants; $F_{1,2}$, commercial AMF inocula; $R_{1,2}$, Bradyrhizobium japonicum inocula; Soybean cultivars: Aliz and Emese; WW, well-watered conditions; DS, drought stress. investigation of qualitative and quantitative yield indicators in horticulture, fruit or ornamental production (Albrechtova et al., 2012; Bona et al., 2016; Engel et al., 2016).

In the present study symbiotic effectiveness was investigated with 20-20 measured parameters on drought-selected soybean hosts during their vegetative and early reproductive stages, with special regard to the compatibility of dual and tripartite symbiotic agents. Most of the measured parameters confirmed the beneficial effect of inoculation with symbionts on plant development and drought tolerance (Figures 1-4). Similar to other observations (Okereke et al., 2001; Meghvansi et al., 2008), the responses of soybean to microbial inoculation depended considerably on the rhizobial strains, on the fungal products and also on the cultivars. The present investigations showed that the benefits of symbiosis were more obvious in the case of plants singly or co-inoculated with AMF than for those inoculated solely with rhizobium (Figure 1 and Tables 1, 2). After single inoculation with products containing AM fungal species $\left(\mathrm{F}_{1}\right.$ and $\left.\mathrm{F}_{2}\right)$ the increase in shoot and $\mathrm{RDW}$, LA and $\mathrm{C}_{\mathrm{R}}$ was higher than in rhizobium only treatments (Figures 1A-D). With the exception of $C_{R}$ these parameters differed slightly between soybean varieties. Such functional differences also occurred between the AMF treatments as reported earlier (Louis and Lim, 1988; Antunes et al., 2006; de Varennes and Goss, 2007). Infection with Bradyrhizobium clearly enhanced the leaf nitrogen content, but AMF colonization reduced the concentration of nitrogen and phosphorus due to the dilution effect of higher plant biomass (Tables 1, 2). In the Compatibility experiment, the results obtained for ARA and plant nitrogen content revealed clear differences in the effect of the two rhizobial inoculants on plant nutrition. Despite their lower colonization values, plants treated with the AMF inoculum $F_{1}$ had a higher growth rate than those inoculated with $F_{2}$ (Figures 1A-C). No AM fungal colonization was observed during the experimental period on the great majority of the roots in $\mathrm{F}_{1}$-treated pots. The extra biomass production caused by $\mathrm{F}_{1}$ could be due to the high organic content of the biofertilizer. The higher number of species in the $\mathrm{F}_{2}$ product could lead to higher infectivity and effectiveness, so $\mathrm{F}_{2}$ could be more successful in developing a compatible relationship.

Numerous field and pot trials proved that AMF inoculation significantly increased soybean yields (by 20-50\%); however, the response varied with soil type, fertilization and the origin of the symbiotic partners (Porcel and Ruiz-Lozano, 2004; Meghvansi et al., 2008; Kaschuk et al., 2010; Wang et al., 2011). It was found that inoculation with Bradyrhizobium sp. or Glomus mosseae in pot culture was able to inhibit both pathogenic infection with Cylindrocladium parasiticum and the development of the parasite in soybean roots, while co-inoculation was more effective than the use of any of the microsymbionts alone (Gao et al., 2012). The positive interaction between the microsymbionts was indicated by the extra biomass production, the increased number of nodules and the richness of AMF root structures (Louis and Lim, 1988; Xie et al., 1995). However, the carbon cost of mycorrhizal fungi requires the delivery of $4-20 \%$ of the photosynthetically fixed carbon from the host plants to the symbiotic partner (Grimoldi et al., 2006; Kaschuk et al., 2009). According to Minchin et al. (1981), 
as much as $25 \%$ of net photosynthates may be appropriated for biological nitrogen fixation. Furthermore, the cost of two independent microsymbiotionts in tripartite associations may be cumulative (Harris et al., 1985). Although multiple inoculation may result in decreased biomass production or unfavorable microbial parameters, the present results indicated that microbial inoculation can improve photosynthetic efficiency both in well-watered soils and under drought stress, though this effect depends on the inoculants (Figure 3D). The increased photosynthetic activity and root functionality of bacteria or AMF treated hosts resulted in higher biomass production compared to control plants. However, co-inoculation with rhizobial and AM fungal strains did not produce significantly further more biomass in pumice (Figure 1A); moreover, in the case of dual inoculation, AMF root colonization exhibited a slight decrease.

Fluorescence kinetics and the root electrical capacitance methods proved to be useful tools for the in situ monitoring of the effect of several stress factors and for the selection of stress-tolerant cultivars or effective microbial strains (Solti et al., 2014; Cseresnyés et al., 2016, 2018), but less research has targeted the characterization of differences between different genotypes of crop species (Barócsi, 2013). The rate of photosynthesis is influenced by environmental conditions (e.g., water, temperature, nutrients, light and $\mathrm{CO}_{2}$ ) and internal factors, such as the nutrient concentration of the tissues and the sink strength stimulated by the carbon cost of symbiotic associations (Kaschuk et al., 2009). In the present experiments significant differences were found both in the chlorophyll fluorescence and $C_{R}$ values of different microbial treatments and soybean cultivars. Of the two varieties, the Aliz had higher photochemical efficiency, which represented an inverse tendency compared to the LA values. Both in pumice and organic soil $\mathrm{C}_{\mathrm{R}}$ was closely correlated with root biomass (Cseresnyés et al., 2016). However, the measured values were the joint result of root activity, the activity of root-associated symbionts and the soil. This means that at the same stage of development, under similar soil conditions, both rhizobial nodules and AMF extraradical hyphal network may have a beneficial effect on active root surface area. The same root biomass is associated with higher $C_{R}$ in the case of inoculated plants and with lower values in response to drought stress (Cseresnyés et al., 2013). The increased water uptake of inoculated plants is presumably due to the enhanced root-soil interface caused by the external fungal hyphae and the root nodulation. It was found earlier that eight soybean cultivars could be classified into different drought-tolerance groups on the basis of $\mathrm{C}_{\mathrm{R}}$ showing a strong correlation with cultivar-specific root growth and biomass production under both well-watered and drought conditions (Cseresnyés et al., 2016). Several studies proved that advanced root properties such as greater depth and larger root system with more root hairs are advantageous under water deficit (Ku et al., 2013; Kumagai and Sameshima, 2014; Cseresnyés et al., 2016). It was also found that the effects of co-inoculation were related to the root morphology of soybean genotypes (Wang et al., 2011, 2016). For example, deeply rooted hosts benefited more than shallowly rooted ones. DS impeded plant growth in all the treatments for both cultivars (Figures 2A-D) (Porcel and Ruiz-Lozano, 2004; Masuda and Goldsmith, 2009). Similar to other investigations (Ruiz-Lozano et al., 2001; Porcel and Ruiz-Lozano, 2004), mycorrhizal associations seem to have played an important role in the drought stress tolerance of soybean. Strong linear $C_{R}-R D W$ and $C_{R}$-LA relationships were revealed in the Drought Stress experiment, (Figures 4A,B). As the leaves vaporize the water taken up by the roots, LA should be proportional to the absorptive surface area of the root system involved in the mycorrhizosphere, being manifested as a correlation between $C_{R}$ and LA. In the case of drought stress, the beneficial effect of inoculation was mostly more pronounced in Emese than in Aliz. Emese produced a bigger root system and was more resistant to drought stress than Aliz, where the levels of RSR and $C_{R}$ were lower (Figure 2E). Although Emese lost more water from its leaves due to the larger biomass, it did not differ from Aliz in terms of DSS (Figure 3B). The loss of biomass caused by drought was also lower in the case of Emese, while the mycorrhizal dependence of Aliz increased under drought. These results suggest that the functional properties of the roots may significantly affect the susceptibility of cultivars to microsymbionts, which could also influence the development of cultivar-specific stress tolerance (Wang et al., 2016). It has been reported that grasses having hairy and bushy fibrous roots with a large surface for uptake are less mycotroph than the tap-rooted plants in mycotrophic plant families (Muleta, 2010). In a tripartite symbiotic association, AM fungi respond more sensitively to differences in the (functional) properties of the root between species and varieties than rhizobia (Wang et al., 2016). The establishment of symbiosis enlarges the active root surface area responsible for water and nutrient uptake, which can be detected by measuring $C_{R} \cdot C_{R}$ measurements are sufficiently sensitive to detect differences in the infectivity of AM strains (Takács et al., 2014). No data on the $C_{R}$ of nodulated roots have yet been published. In the present experiments plants infected with rhizobium had significantly higher $C_{R}$ than the control despite the similar RDW (Figure 4B). Nodules and the extraradical hyphal network add to $\mathrm{C}_{\mathrm{R}}$ by enlarging the absorbing surface.

It should be noted that when evaluating the beneficial effects of inoculation one should allow for the carriers of the commercial products, which may contain nutrients. The extra biomass production caused by the $\mathrm{F}_{1}$ AMF biofertilizer could be the result of its high organic material content. Multifactorial investigations are needed for the determinination of host compatibility and the efficacy of microbial inocula on plant production, including the measurement of plant growth and functional parameters, with both in situ and destructive methods.

In the field, the symbiotic effectiveness of rhizobial strains or AMF inoculants and their competitiveness can be achieved by superior microsymbionts originated from natural or managed selection. However, no single AMF or rhizobium strain is likely to be effective in all soils under any conditions and on any plant host, therefore no commercial fertilizer can be expected to be ideal for every field, despite containing multiple strains or species. 
All the products need to be tested before application and it is possible that no suitable commercial fertilizer will be adequate for a specific purpose. In this case, the managed selection of strains originating from the indigenous microbial community could be the best solution.

In low-input agricultural systems, research on cooperation between different microbial symbionts is a key to understanding how the health and productivity of the plant is supported (Mahdi et al., 2010; Bhardwaj et al., 2014). Increasing the fitness and vitality of host plants to environmental stress by means of site-adapted, compatible symbiotic partnerships could be a new strategy for mitigating the impacts of environmental stress factors on plant production (Gianinazzi et al., 2010). Little differences in the root properties of drought tolerant cultivars may cause significant differences in the growth and physiological parameters that are used to describe symbiotic relationships. Endurance of even drought tolerant cultivars can be improved by inoculation with AMF or nitrogen fixing bacteria. In well-watered conditions, the tripartite association did not show the synergistic effect on the plants, so the benefits produced by commercial AMF products may have been partially originated from their carrier. The efficiency of these biofertilizers should therefore be checked before large scale application. The present results show the potential of $\mathrm{C}_{\mathrm{R}}$ measurements to monitor the effect of symbiotic factors influencing root growth and biomass production. This in situ technique provides an opportunity to follow the temporal

\section{REFERENCES}

Albareda, M., Rodríguez-Navarro, D. N., and Temprano, F. J. (2009). Soybean inoculation: dose, $\mathrm{N}$ fertilizer supplementation and rhizobia persistence in soil. Field Crops Res. 113, 352-356. doi: 10.1016/j.fcr.2009.05.013

Albrechtova, J., Latr, A., Nedorost, L., Pokluda, R., Posta, K., and Vosatka, M. (2012). Dual inoculation with mycorrhizal and saprotrophic fungi applicable in sustainable cultivation improves the yield and nutritive value of onion. ScientificWorldJournal 2012:374091. doi: 10.1100/2012/374091

Antunes, P. M., Deaville, D., and Goss, M. J. (2006). Effect of two AMF life strategies on the tripartite symbiosis with Bradyrhizobium japonicum and soybean. Mycorrhiza 16, 167-173. doi: 10.1007/s00572-005-0028-3

Appunuu, C., Zoue, A. N., and Laguerre, G. (2008). Genetic diversity of native Bradyrhizobia isolated from soybeans (Glycine max L.) in different agriculturalecological-climatic regions of India. Appl. Env. Ecol. 74, 5991-5996. doi: 10. 1128/AEM.01320-08

Artusson, V., Finlay, R. D., and Jansson, J. K. (2006). Interactions between arbuscular mycorrhizal fungi and bacteria and their potential for stimulating plant growth. Environ. Microbiol. 8, 1-10. doi: 10.1111/j.1462-2920.2005. 00942.x

Balog, A., Loxdale, H. D., Bálint, J., Benedek, K., Szabó, K. A., Jánosi-Rancz, K. T., et al. (2017). The arbuscular mycorrhizal fungus Rhizophagus irregularis affects arthropod colonization on sweet pepper in both the field and greenhouse. J. Pest Sci. 90, 935-946. doi: 10.1007/s10340-017-0844-1

Barea, J. M. (1997). “Mycorrhiza-bacteria interactions on plant growth promotion,” in Plant Growth Promoting Rhizobacteria, eds A. K. Ogoshi, A. K. Kobayashi, Y. Homma, Y. F. Kodama, N. Kondo, and S. Akino (Paris: OECD Press), 150-158.

Barócsi, A. (2013). Intelligent, net or wireless enabled fluorosensors for high throughput monitoring of assorted crops. Measure. Sci. Technol. 24:025701. doi: 10.1088/0957-0233/24/2/025701

Barócsi, A., Lenk, S., Kocsányi, L., and Buschmann, C. (2009). Excitation kinetics during induction of chlorophyll a fluorescence. Photosynthesis 47, 104-111. doi: 10.1007/s11099-009-0016-5 changes in root activity and to select efficient plant-microbe partnerships.

\section{AUTHOR CONTRIBUTIONS}

TT supervised the project, conducted the pot experiments, discussed the results, and wrote the paper. IC was responsible for $C_{R}$ measurements and data evaluation. TT, RK, IP, BK, TS-K, and AF designed and carried out the investigations on the symbiotic microorganisms and on the plants. All authors read the manuscript and approved the submission.

\section{FUNDING}

This study was funded by the Research Institute of Organic Agriculture, the National Research, Development and Innovation Fund of Hungary (Project Nos. 115714, financed under the K-16 funding scheme) and Bolyai János Research Scholarships of the Hungarian Academy of Sciences.

\section{ACKNOWLEDGMENTS}

The authors thank the reviewers for helpful comments, and Barbara Harasztos for improving the English in this paper.

Behie, S. W., and Bidochka, M. J. (2014). Nutrient transfer in plant-fungal symbioses. Trends Plant Sci. 19, 734-740. doi: 10.1016/j.tplants.2014.06.007

Bethlenfalvay, G. J., Milford, S., Brown, K. L. M., and Stafford, A. E. (1987). Glycine Glomus- Rhizobium symbiosis. Plant Physiol. 85, 115-119. doi: 10.1104/pp.85. 1.115

Bhardwaj, D., Ansari, M. W., Sahoo, R. K., and Tuteja, N. (2014). Biofertilizers function as key player in sustainable agriculture by improving soil fertility, plant tolerance and crop productivity. Microb. Cell Fact. 13:66. doi: 10.1186/14752859-13-66

Biró, B., Köves-Péchy, K., Vörös, I., Takács, T., Eggenberger, P., and Strasser, R. J. (2000). Interrelations between Azospirillum and Rhizobium nitrogen fixers and arbuscular mycorrhizal fungi in the rhizosphere of alfalfa in sterile AMF free or normal conditions. Appl. Soil Ecol. 15, 159-168. doi: 10.1016/S0929-1393(00) 00092-5

Bona, E., Lingua, G., and Todeschini, V. (2016). "Effect of bioinoculants on the quality of crops," in Bioformulations: For Sustainable Agriculture, ed. R. Balestrini (New Delhi: Springer), doi: 10.1007/978-81-322-2779-35

Bouslama, M., and Schapaugh, W. T. (1984). Stress tolerance in soybeans. Part 1. Evaluation of three screening techniques for heat and drought tolerance. Crop Sci. 24, 933-937. doi: 10.2135/cropsci1984.0011183X002400050026x

Brundrett, M. C. (2009). Mycorrhizal associations and other means of nutrition of vascular plants: understanding the global diversity of host plants by resolving conflicting information and developing reliable means of diagnosis. Plant Soil 320, 37-77. doi: 10.1007/s11104-008-9877-9

Cameron, D. D., Neal, A. L., van Wees, S. C., and Ton, J. (2013). Mycorrhizainduced resistance: more than the sum of its parts? Trends Plant Sci. 18, 539-545. doi: 10.1016/j.tplants.2013.06.004

Cavagnaro, T. R., Smith, F. A., Smith, S. E., and Jakobsen, I. (2005). Functional diversity in arbuscular mycorrhizas: exploitation of soil patches with different phosphate enrichment differs among fungal species. Plant Cell Environ. 28, 642-650. doi: 10.1111/j.1365-3040.2005.01310.x

Cely, M. V. T., de Oliveira, A. G., de Freitas, V. F., de Luca, M. B., Barazetti, A. R., dos Santos, I. M. O., et al. (2016). Inoculant of arbuscular mycorrhizal 
fungi (Rhizophagus clarus) increase yield of soybean and cotton under field conditions. Front. Microbiol. 7:720. doi: 10.3389/fmicb.2016.00720

Chloupek, O. (1972). The relationship between electric capacitance and some other parameters of plant roots. Biol. Plant. 14, 227-230. doi: 10.1007/BF02921255

Chloupek, O., Dostál, V., Støeda, T., Psota, V., and Dvoøáèková, O. (2010). Drought tolerance of barley varieties in relation to their root system size. Plant Breed. 129, 630-636. doi: 10.1111/j.1439-0523.2010.01801.x

Cseresnyés, I., Rajkai, K., and Takács, T. (2016). Indirect monitoring of root activity in soybean cultivars under contrasting moisture regimes by measuring electrical capacitance. Acta Physiol. Plant. 38:121. doi: 10.1007/s11738-016-2149-z

Cseresnyés, I., Szitár, K., Rajkai, K., Füzy, A., Mikó, P., Kovács, R., et al. (2018). Application of electrical capacitance method for prediction of plant root mass and activity in field-grown crops. Front. Plant Sci. 9:93. doi: 10.3389/fpls.2018. 00093

Cseresnyés, I., Takács, T., Végh, K. R., Anton, A., and Rajkai, K. (2013). Electrical impedance and capacitance method: a new approach for detection of functional aspects of arbuscular mycorrhizal colonization in maize. Eur. J. Soil Biol. 54, 25-31. doi: 10.1016/j.ejsobi.2012.11.001

de Varennes, A., and Goss, M. J. (2007). The tripartite symbiosis between legumes, rhizobia and indigenous mycorrhizal fungi is more efficient in undisturbed soil. Soil Biol. Biochem. 39, 2603-2607. doi: 10.1016/j.soilbio.2007.05.007

Denison, R. F., and Kiers, E. T. (2011). Life histories of symbiotic rhizobia and mycorrhizal fungi. Curr. Biol. 21, 775-785. doi: 10.1016/j.cub.2011.06.018

Domokos, E., Jakab-Farkas, L., Darkó, B., Bíró-Janka, B., Mara, G., Albert, C., et al. (2018). Increase in artemisia annua plant biomass artemisinin content and guaiacol peroxidase activity using the arbuscular mycorrhizal fungus Rhizophagus irregularis. Front. Plant Sci. 9:478. doi: 10.3389/fpls.2018.00478

Engel, R., Szabó, K., Abrankó, L., Rendes, K., Füzy, A., and Takaìcs, T. (2016). Effect of arbuscular mycorrhizal fungi on the growth and polyphenol profile of marjoram, lemon balm, and marigold. J. Agric. Food Chem. 64, 3733-3742. doi: 10.1021/acs.jafc.6b00408

Farooq, M., Gogoi, N., Barthakur, S., Baroowa, B., Bharadwaj, N., Alghamdi, S. S., et al. (2016). Drought stress in grain legumes during reproduction and grain filling. J. Agro. Crop Sci. 203, 81-102. doi: 10.1111/jac.12169

Fauvart, M., and Michiels, J. (2008). Rhizobial secreted proteins as determinants of host specificity in the rhizobium-legume symbiosis. FEMS Microbiol. Lett. 285, 1-9. doi: 10.1111/j.1574-6968.2008.01254.x

Gao, X., Lu, X., Wu, M., Zhang, H., Pan, R., Tian, J., et al. (2012). Co-inoculation with rhizobia and AMF inhibited soybean red crown rot: from field study to plant defense-related gene expression analysis. PLoS One 7:e33977. doi: 10. 1371/journal.pone.0033977

Gianinazzi, S., Gollotte, A., Binet, M. N., van Tuinen, D., Redecker, D., and Wipf, D. (2010). Agroecology: the key role of arbuscular mycorrhizas in ecosystem services. Mycorrhiza 20, 519-530. doi: 10.1007/s00572-010-0333-3

González, L., and González-Vilar, M. (2007). "Determination of relative water content," in Handbook of Plant Ecophysiology Techniques, ed. M. J. R. Reigoza (Dordrecht: Kluwer Academic Publishers), 207-212. doi: 10.1007/0-30648057-3_14

Gosling, P., Hodge, A., Goodlass, G., and Bending, G. D. (2006). Arbuscular mycorrhizal fungi and organic farming. Agric. Ecosyst. Environ. 113, 17-35. doi: 10.1016/j.agee.2005.09.009

Grimoldi, A. A., Kavanová, M., Lattanzi, F. A., Schäufele, R., and Schnyder, H. (2006). Arbuscular mycorrhizal colonization on carbon economy in perennial ryegrass: quantification by $13 \mathrm{CO} 2 / 12 \mathrm{CO} 2$ steady-state labelling and gas exchange. New Phytol. 172, 544-553. doi: 10.1111/j.1469-8137.2006.01853.x

Hardy, R. W. F., Holsten, R. D., Jackson, E. K., and Burns, R. C. (1968). Acetylene - ethylene assay for N2 fixation: laboratory and field evaluation. Plant Physiol. 43, 1185-1207. doi: 10.1104/pp.43.8.1185

Harris, D., Pacovsky, R. S., and Paul, E. A. (1985). Carbon economy of soybeanrhizobium-glomus associations. New Phytol. 101, 427-440. doi: 10.1111/j.14698137.1985.tb02849.x

Herrera-Peraza, R. A., Hamel, C., Fernández, F., Ferrer, R. L., and Furrazola, E. (2011). Soil-strain compatibility: the key to effective use of arbuscular mycorrhizal inoculants? Mycorrhiza 21, 183-193. doi: 10.1007/s00572-010$0322-6$

Hodge, A., and Storer, K. (2015). Arbuscular mycorrhiza and nitrogen: implications for individual plants through to ecosystems. Plant Soil 386, 1-19. doi: $10.1007 / \mathrm{s} 11104-014-2162-1$
IUSS Working Group WRB (2015). "World Reference Base (WRB) for Soil Resources 2014, update 2015," in Proceedings of the International soil classification system for naming soils and creating legends for soil maps. World Soil Resources Reports 106, (Rome: FAO).

Jakobsen, I., Abbott, L. K., and Robson, A. D. (1992). External hyphae of vesiculararbuscular mycorrhizal fungi associated with Trifolium subterraneum L. I. Spread of hyphae and phosphorus inflow into roots. New Phytol. 120, 371-380. doi: 10.1111/j.1469-8137.1992.tb01077.x

Johnson, N. C., Graham, J. H., and Smith, F. A. (1997). Functioning and mycorrhizal associations along mutualism-parasitism continuum. New Phytol. 135, 575-586. doi: 10.1046/j.1469-8137.1997.00729.x

Kaschuk, C., Kuyper, T. W., Leffelaar, P. A., Hungria, M., and Giller, K. E. (2009). Are the rates of photosynthesis stimulated by the carbon sink strength of rhizobial and arbuscular mycorrhizal symbioses? Soil Biol. Biochem. 41, 1233-1244. doi: 10.1016/j.soilbio.2009.03.005

Kaschuk, G., Leffelaar, P. A., Giller, K. E., Alberton, O., Hungria, M., and Kuyper, T. W. (2010). Responses of legumes to rhizobia and arbuscular mycorrhizal fungi: a meta-analysis of potential photosynthate limitation of symbioses. Soil Biol. Biochem. 42, 125-127. doi: 10.1016/j.soilbio.2009.10.017

Kiers, E. T., West, S. A., and Denison, R. F. (2002). Mediating mutualisms: the influence of farm management practices on the evolutionary maintenance of symbiont co-operation. J. Appl. Ecol. 39, 745-754. doi: 10.1046/j.1365-2664. 2002.00755.x

Kjeldahl, J. Z. (1883). A new method for the determination of nitrogen in organic bodies. Z. Anal. Chem. 22, 366-383. doi: 10.1007/BF01338151

Ku, Y.-S., Au-Yeung, W.-K., Yung, Y.-L., Li, M.-W., Wen, C.-Q., Liu, X., et al. (2013). "Drought stress and tolerance in soybean," in A Comprehensive Survey of International Soybean Research - Genetics, Physiology, Agronomy and Nitrogen relationships, ed. J. E. Board (New York, NY: InTech), 209-237. doi: 10.5772/ 52945

Kumagai, E., and Sameshima, R. (2014). Genotypic differences in soybean yield responses to increasing temperature in a cool climate are related to maturity group. Agric. Forest Meteorol. 198-199, 265-272. doi: 10.1016/j.agrformet.2014. 08.016

Lisette, J., Xavier, C., and Germida, J. J. (2003). Selective interactions between arbuscular mycorrhizal fungi and Rhizobium leguminosarum bv. viceae enhance pea yield and nutrition. Biol. Fertil. Soils 37, 261-267. doi: 10.1007/s00374-0030605-6

Louis, I., and Lim, G. (1988). Differential response in growth and mycorrhizal colonisation of soybean to inoculation with two isolates of Glomus clarum in soils of different P availability. Plant Soil 112, 37-43. doi: 10.1007/BF0218 1750

Mahdi, S. S., Hassan, G. I., Samoon, S. A., Rather, H. A., Dar, S. A., and Zehra, B. (2010). Bio-fertilizers in organic agriculture. J. Phytol. 2, 42-54.

Marschner, H. (1997). "The soil-root interface (rhizosphere) in relation to mineral nutrition," in Mineral Nutrition of Higher Plants, ed. H. Marschner (London: Academic Press), 537-594.

Masuda, T., and Goldsmith, P. D. (2009). World soybean production: Area harvested, yield, and long-term projections. IAMA 12, 143-162.

Meghvansi, M. K., Prasad, K., Harwani, D., and Mahna, S. K. (2008). Response of soybean cultivars toward inoculation with three arbuscular mycorrhizal fungi and Bradyrhizobium japonicum in the alluvial soil. Eur. J. Soil Biol. 44, 316-323. doi: $10.1016 /$ j.ejsobi.2008.03.003

Menge, D. N. L., Hedin, L. O., and Pacala, S. W. (2012). Nitrogen and phosphorus limitation over long-term ecosystem development in terrestrial ecosystems. PLoS One 7:e42045. doi: 10.1371/journal.pone.0042045

Michel, B. E. R., and Kaufmann, M. R. (1973). The osmotic potential of polyethylene glycol 6000. Plant Physiol. 51, 914-916. doi: 10.1104/pp.51.5.914

Miller, A. J., and Cramer, M. D. (2004). Root nitrogen acquisition and assimilation. Plant Soil 274, 1-36. doi: 10.1007/1-4020-4099-7_1

Minchin, F. R., Summerfield, R. J., Hadley, P., Roberts, E. H., and Rawsthorne, S. (1981). Carbon and nitrogen nutrition of nodulated roots of grain legumes. Plant Cell Environ. 4, 5-26. doi: 10.1111/j.1365-3040.1981. tb00831.x

Muleta, D. (2010). "Legume responses to arbuscular mycorrhizal fungi inoculation in sustainable agriculture," in Inoculation Microbes for Legume Improvement, eds M. S. Khan, A. Zaidi, and J. Musarrat (Wien: Springer), 293-323. doi: 10.1007/978-3-319-59174-2_10 
Munkvold, L., Kjoller, R., Vestberg, M., Rosendahl, S., and Jakobsen, I. (2004). High functional diversity within species of arbuscular mycorrhizal fungi. New Phytol. 164, 357-364. doi: 10.1111/j.1469-8137.2004.01169.x

Neves, M. C. P., and Rumjanek, N. G. (1997). Diversity and adaptability of soybean and cowpea rhizobia in tropical soils. Soil Biol. Biochem. 29, 889-895. doi: 10.1016/S0038-0717(96)00205-2

OECD-FAO (2018). OECD-FAO Agricultural Outlook 2018-2027. Paris: OECD Publishing. doi: 10.1787/agr_outlook-2018-en

Ohyama, T., Minagawa, R., Ishikawa, S., Yamamoto, M., Hung, N. V. P., Ohtake, N., et al. (2013). "Soybean seed production and nitrogen nutrition," in A Comprehensive Survey of International Soybean Research - Genetics, Physiology, Agronomy and Nitrogen Relationships, ed. J. E. Board (Rijeka: InTech), 115-157. doi: $0.5772 / 52287$

Okereke, G. U., Onochie, C., Onunkwo, A., and Onyeagba, E. (2001). Effectiveness of foreign bradyrhizobia strains in enhancing nodulation, dry matter and seed yield of soybean (Glycine max L.) cultivars in Nigeria. Biol. Fertil. Soils 33, 3-9. doi: $10.1007 /$ s003740000264

Ossler, J. N., Zielinski, C. A., and Heath, K. D. (2015). Tripartite mutualism: Facilitation or trade-offs between rhizobial and mycorrhizal symbionts of legume hosts. Am. J. Bot. 102, 1332-1341. doi: 10.3732/ajb.1500007

Phillips, J. M., and Hayman, D. S. (1970). Improved procedures for clearing roots and staining parasitic and vesicular-arbuscular mycorrhizal fungi for rapid assessment of infection. Trans. Brit. Mycol. Soc. 55, 158-161. doi: 10.1016/ S0007-1536(70)80110-3

Plenchette, C., Fortin, J. A., and Furlan, V. (1983). Growth responses of several plant species to mycorrhizae in a soil of moderate P-fertility. Plant Soil 70, 199-209. doi: 10.1007/BF02374780

Porcel, R., and Ruiz-Lozano, J. M. (2004). Arbuscular mycorrhizal influence on leaf water potential, solute accumulation, and oxidative stress in soybean plants subjected to drought stress. J. Exp. Bot. 55, 1743-1750. doi: 10.1093/jxb/erh188

Purcell, L. C., King, C. A., and Ball, R. A. (2000). Soybean cultivar differences in ureides and the relationship to drought tolerant nitrogen fixation and manganese nutrition. Crop Sci. 40, 1062-1070. doi: 10.2135/cropsci2000. 4041062x

Rapparini, F., and Peñuelas, J. (2014). "Mycorrhizal fungi to alleviate drought stress on plant growth," in Use of Microbes for the Alleviation of Soil Stresses, ed. M. Miransari (New York, NY: Springer), 21-42. doi: 0.1007/978-1-4614-9466-9_2

Ruiz-Lozano, J. M., Collados, C., Barea, J. M., and Azcón, R. (2001). Arbuscular mycorrhizal symbiosis can alleviate drought-induced nodule senescence in soybean plants. New Phytol. 151, 493-502. doi: 10.1046/j.0028-646x.2001. 00196.x

Schneider, K. D., Derek, H., Lynch, K., Dunfield, K., Khosla, J., Jansa, R., et al. (2015). Farm system management affects community structure of arbuscular mycorrhizal fungi. Appl. Soil. Ecol. 96, 192-200. doi: 10.1016/j.apsoil.2015. 07.015

Silvente, S., Sobolev, A. P., and Lara, M. (2012). Metabolite adjustments in drought tolerant and sensitive soybean genotypes in response to water stress. PLoS One 7:e38554. doi: 10.1371/journal.pone.0038554
Solti, Á, Lenk, S., Mihailova, G., Mayer, P., Barócsi, A., and Georgieva, K. (2014). Effects of habitat light conditions on the excitation quenching pathways in desiccating Haberlea rhodopensis leaves: an intelligent fluoro sensor study. J. Photochem. Photobiol. B Biol. 130, 217-225. doi: 10.1016/j.jphotobiol.2013. 11.016

Takács, T., Füzy, A., Rajkai, K., and Cseresnyés, I. (2014). Investigation of arbuscular mycorrhizal status and functionality by electrical impedance and capacitance measurement. Acta Biol. Szeged. 58, 55-59.

Trouvelot, A., Kought, J. L., and Gianinazzi-Pearson, V. (1986). "Mesure du taux de mycorrhization VA d'un systéme radiculaire. Recherche de méthodes d'estimation ayant une signification fonctionnelle," in Ler Symposium Europeen sur les Mycorrhizes, eds V. Gianinazzi-Pearson and S. Gianinazzi (Paris: INRA), 217-221.

Vincent, J. M. (1970). A Manual for the Practical Study of the Root Nodule Bacteria. Oxford-Edinburgh: Blackwell Scientific Publ.

Vosátka, M., Látr, A., Gianinazzi, S., and Albrechtová, J. (2012). Development of arbuscular mycorrhizal biotechnology and industry: current achievements and bottlenecks. Symbiosis 58, 29-37. doi: 10.1007/s13199-0120208-9

Wahbi, S., Maghraoui, T., Hafidi, M., Sanguin, H., Oufdou, K., Prin, Y., et al. (2016). Enhanced transfer of biologically fixed $\mathrm{N}$ from faba bean to intercropped wheat through mycorrhizal symbiosis. Appl. Soil Ecol. 107, 91-98. doi: 10.1016/j. apsoil.2016.05.008

Wang, X., Pan, Q., Chen, F., Yan, X., and Liao, H. (2011). Effects of co-inoculation with arbuscular mycorrhizal fungi and rhizobia on soybean growth as related to root architecture and availability of $\mathrm{N}$ and P. Mycorrhiza 21, 173-181. doi: 10.1007/s00572-010-0319-1

Wang, X., Zhao, S., and Bücking, H. (2016). Arbuscular mycorrhizal growth responses are fungal specific but do not differ between soybean genotypes with different phosphate efficiency. Ann. Bot. 118, 11-21. doi: 10.1093/aob/ mcw074

Xie, Z., Staehelin, C., Vierheilig, H., Wiemken, A., Jabbouri, S., Broughton, W. J., et al. (1995). Rhizobial nodulation factors stimulate mycorrhizal colonization of nodulating and non-nodulating soybeans. Plant Physiol. 108, 1519-1525. doi: $10.1104 /$ pp.108.4.1519

Conflict of Interest Statement: The authors declare that the research was conducted in the absence of any commercial or financial relationships that could be construed as a potential conflict of interest.

Copyright (C) 2018 Takács, Cseresnyés, Kovács, Parádi, Kelemen, Szili-Kovács and Füzy. This is an open-access article distributed under the terms of the Creative Commons Attribution License (CC BY). The use, distribution or reproduction in other forums is permitted, provided the original author(s) and the copyright owner(s) are credited and that the original publication in this journal is cited, in accordance with accepted academic practice. No use, distribution or reproduction is permitted which does not comply with these terms. 